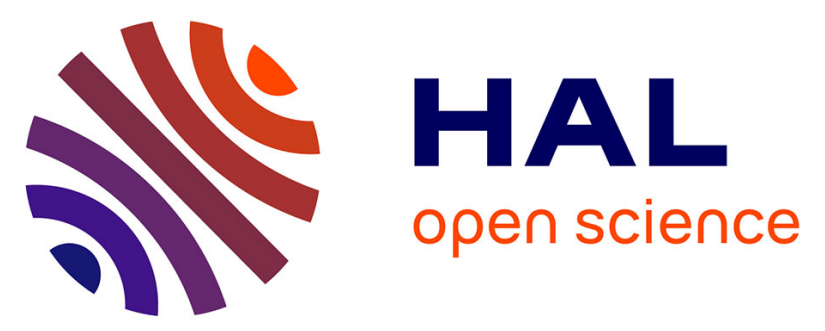

\title{
Micromechanics-Based Damage Analysis of Fracture in Ti5553 Alloy with Application to Bolted Sectors
}

Mohamed Ben Bettaieb, Thibaut van Hoof, Hans Minnebo, Thomas Pardoen, Philippe Dufour, Pascal J. Jacques, Anne-Marie Habraken

\section{- To cite this version:}

Mohamed Ben Bettaieb, Thibaut van Hoof, Hans Minnebo, Thomas Pardoen, Philippe Dufour, et al.. Micromechanics-Based Damage Analysis of Fracture in Ti5553 Alloy with Application to Bolted Sectors. Journal of Materials Engineering and Performance, 2015, 24 (3), pp.1262-1278. 10.1007/s11665015-1383-7 . hal-01201780

\section{HAL Id: hal-01201780 \\ https://hal.science/hal-01201780}

Submitted on 18 Sep 2015

HAL is a multi-disciplinary open access archive for the deposit and dissemination of scientific research documents, whether they are published or not. The documents may come from teaching and research institutions in France or abroad, or from public or private research centers.
L'archive ouverte pluridisciplinaire HAL, est destinée au dépôt et à la diffusion de documents scientifiques de niveau recherche, publiés ou non, émanant des établissements d'enseignement et de recherche français ou étrangers, des laboratoires publics ou privés. 


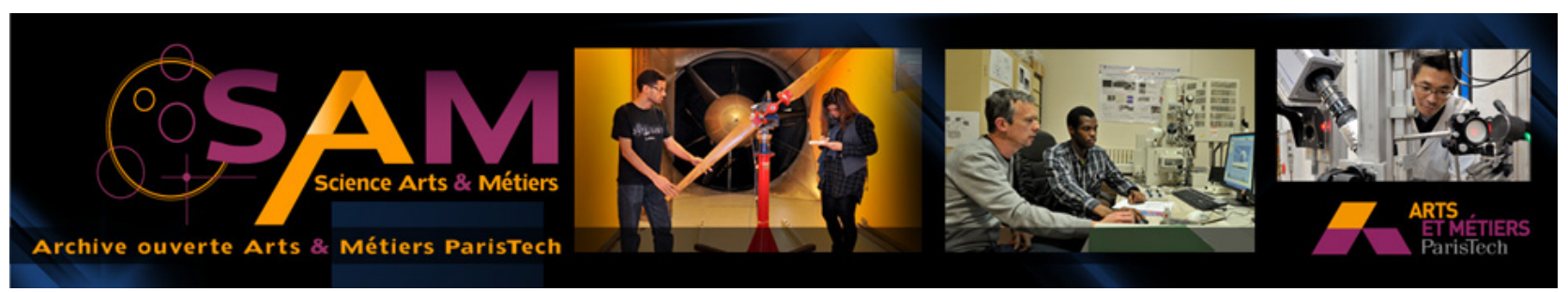

\section{Science Arts \& Métiers (SAM)}

is an open access repository that collects the work of Arts et Métiers ParisTech researchers and makes it freely available over the web where possible.

This is an author-deposited version published in: http://sam.ensam.eu

Handle ID: .http://hdl.handle.net/10985/10046

\section{To cite this version :}

Mohamed BEN BETTAIEB, Thibaut VAN HOOF, Hans MINNEBO, Thomas PARDOEN, Philippe DUFOUR, Pascal J. JACQUES, Anne-Marie HABRAKEN - Micromechanics-Based Damage Analysis of Fracture in Ti5553 Alloy with Application to Bolted Sectors - Journal of Materials Engineering and Performance - Vol. 24, n`3, p.1262-1278 - 2015 


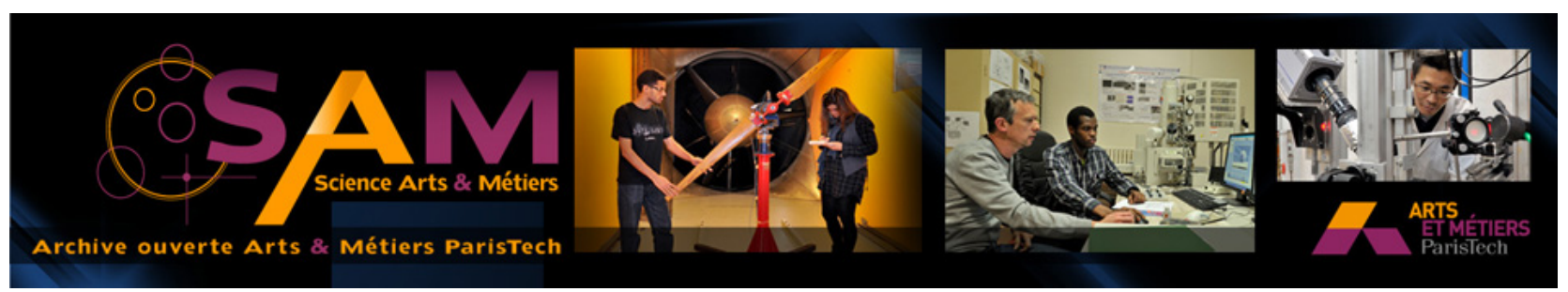

\section{Science Arts \& Métiers (SAM)}

is an open access repository that collects the work of Arts et Métiers ParisTech researchers and makes it freely available over the web where possible.

This is an author-deposited version published in: http://sam.ensam.eu

Handle ID: .http://hdl.handle.net/null

\section{To cite this version :}

Mohamed BEN BETTAIEB, Thibaut VAN HOOF, Hans MINNEBO, Thomas PARDOEN, Philippe DUFOUR, Pascal J. JACQUES, Anne Marie HABRAKEN - Micromechanics-Based Damage Analysis of Fracture in Ti5553 Alloy with Application to Bolted Sectors - Journal of Materials Engineering and Performance - Vol. 24, n`3, p.1262-1278 - 2015 


\title{
Micromechanics-Based Damage Analysis of Fracture in Ti5553 Alloy with Application to Bolted Sectors
}

\author{
Mohamed Ben Bettaieb, ThibautVan Hoof, Hans Minnebo, Thomas Pardoen, Philippe Dufour, Pascal J. Jacques, and Anne Marie Habraken
}

\begin{abstract}
A physics-based, uncoupled damage model is calibrated using cylindrical notched round tensile specimens made of Ti5553 and Ti-6Al-4V alloys. The fracture strain of Ti5553 is lower than for Ti-6Al-4V in the full range of stress triaxiality. This lower ductility originates from a higher volume fraction of damage sites. By proper heat treatment, the fracture strain of Ti5553 increases by almost a factor of two, as a result of a larger damage nucleation stress. This result proves the potential for further optimization of the damage resistance of the Ti5553 alloy. The damage model is combined with an elastoviscoplastic law in order to predict failure in a wide range of loading conditions. In particular, a specific application involving bolted sectors is addressed in order to determine the potential of replacing the Ti-6Al-4V by the Ti5553 alloy.
\end{abstract}

Keywords aircraft engine, complex loading, ductile fracture, FE validation, notched samples, stress triaxiality, Thomason model

\section{Introduction}

Titanium (Ti) alloys are heavily used in aeronautic structures owing to their exceptional strength/density compromise. In particular, titanium constitutes an enabling material for aircraft engine components working at intermediate temperatures (200$400{ }^{\circ} \mathrm{C}$ ). Engine elements undergo severe mechanical loadings, especially under accidental conditions such as during a fan blade out event. The design of structural parts must account for different possible failure scenarios. For almost 50 years, Ti$6 \mathrm{Al}-4 \mathrm{~V}$ is the most common Ti alloy in aerospace components for almost 50 years. It accounts for more than $50 \%$ of the Ti production worldwide. In the temperature range of interest $\left(200-400{ }^{\circ} \mathrm{C}\right)$, Ti-6Al-4V is known to fracture as a result of the growth and coalescence of voids which nucleate at the interface between the $\alpha$ and $\beta$ phases. A recent trend in the aeronautics industry is to monitor the progress in the development of new generations of Ti alloys, such as the Ti5553 (Ref 1, 2), in order to detect potential candidates that could advantageously replace

Mohamed Ben Bettaieb, Division MS2F, Department ArGEnCo, University of Liége, Chemin des Chevreuils 1,4000 Liége,Belgium and ENSAM, Centre de Metz, 4, Rue Augustin FRESNEL, 57078 Metz Cedex 03, France; Thibaut Van Hoof and Hans Minnebo, Centre de Recherches en Aéronautique (CENAERO),Bâtiment Eole,Rue des Fréres Wright 29,B-6041,Gosselies, Belgium; Thomas Pardoen, Philippe Dufour, and Pascal J. Jacques, Institute of Mechanics, Materials and Civil Engineering, Université catholique de Louvain, 1348 Louvain-la-Neuve, Belgium; and Anne Marie Habraken, Division MS2F, Department ArGEnCo, University of Liége, Chemin des Chevreuils 1,4000 Liége, Belgium and Fond National de la Recherche Scientifique (FNRS), Brussels, Belgium.Contact e-mail: mohamed.benbettaieb@ensam.eu.

the Ti-6Al-4V alloy owing to enhanced mechanical performances and/or lower cost.

There are two objectives in the present work. First, an uncoupled ductile fracture model describing the nucleation, growth, and coalescence of voids is proposed, calibrated and validated for both the Ti-6Al-4V and Ti5553 alloys. The selection of the model was guided by the need to find a proper balance between simplicity and accuracy while maintaining a close link with the physics of ductile failure. Second, the potential of the Ti5553 alloy is evaluated in the case of a specific application of bolted sectors of an aircraft engine where the question of ductile fracture is one of the key limiting issues. This application illustrates how the damage model developed in this study can be transferred to real applications.

Two different generic approaches exist to model ductile damage and fracture: the coupled or the uncoupled approach. In the coupled approach, the damage accumulation interacts with the stress and strain evolution owing to a dilatant plasticity formulation. Constitutive models including damage have been formulated based on continuum thermodynamics (e.g., Ref 3, 4) or on micromechanics-based description of voided materials (e.g., Ref 5-10). In the uncoupled approach, the stress and strain fields are assumed to be unaffected by damage. Thus, the damage evolution is calculated using elastoplastic or elastoviscoplastic constitutive equations (Ref 11), as envisioned in the pioneering works of McClintock (Ref 12) and Rice and Tracey (Ref 13), see also recent applications (see Ref 14, 15). The damage evolution can then be computed as a part of the postprocessing analysis. In the present work, the uncoupled approach has been preferred in order to simplify the structural analysis. The choice will be justified also by the fact that damage nucleates relatively late in the deformation process and that the porosity remains quite small until fracture.

Following the pioneering works by Pineau and co-workers (Ref 16), the analysis of damage accumulation and the calibration of the model parameters rely on tensile tests performed on cylindrical notched round specimens, see also (Ref 7, 14, 17-19). A wide range of stress triaxiality, which is the key parameter controlling the rate of damage in plastically deforming materials, can be covered by changing the radius of 
the notch. The elastoviscoplastic material model generated on the basis of the experimental results described in Ref 20 is used to simulate the mechanical tests and to compare the mechanical response of the Ti5553 alloy with the response of the Ti-6Al$4 \mathrm{~V}$ alloy for a specific structural component.

The outline of the paper is the following:

- In section 2, the chemical composition and heat treatments of the different microstructures are presented;

- In section 3, the elastoviscoplastic model and parameters calibration described in Ref 20 are summarized.

- In section 4, the damage model is presented and the parameters are calibrated on the basis of tensile tests performed on smooth and notched specimens.

- In section 5, the difference between the Ti5553 and Ti-6Al-4V alloys is addressed through the analysis of the mechanical response (elastoviscoplastic behavior and fracture modeling) of a component made of bolted sectors of an aircraft engine under various loading conditions.

- Section 6 summarizes the main conclusions of the study.

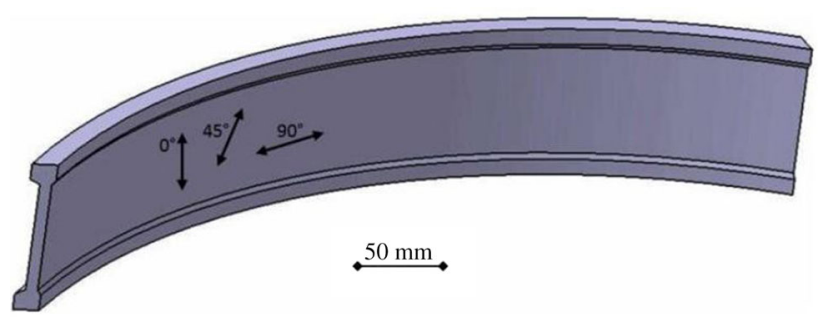

(a)

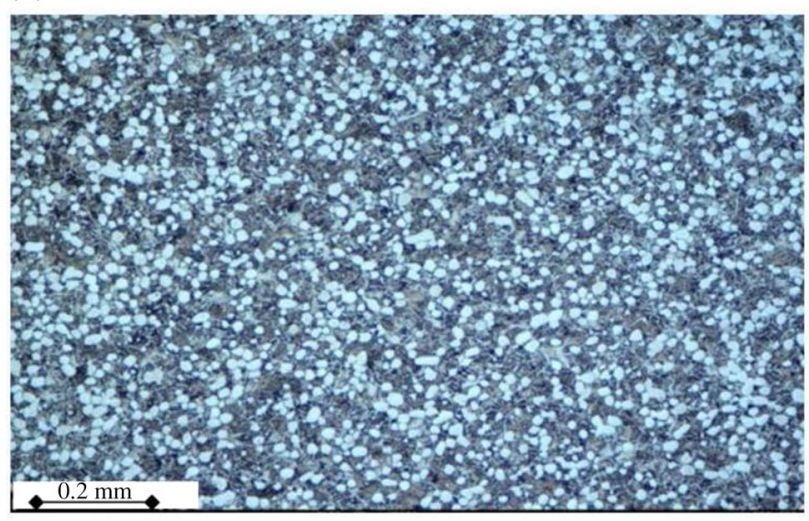

(b)

Fig. 1 Ti-6Al-4V material: (a) forged section with the definition of the extraction directions and (b) microstructure

\subsection{Units}

The international system of units (SI) is used in this paper:

- The stress is expressed in MPa.

- The strain rate is expressed in $\mathrm{s}^{-1}$.

\section{Materials}

As for all metallic alloys, the mechanical properties of $\mathrm{Ti}$ alloys are very sensitive to the initial microstructure, thermomechanical loading history, and chemical composition (Ref 21-24). From a microstructural point of view, the Ti$6 \mathrm{Al}-4 \mathrm{~V}$ and Ti5553 alloys are significantly different in terms of volume fraction and morphology of the primary $\alpha$ phase and transformed $\beta$ phase. A detailed comparison between the microstructures of the two alloys is given in Ref 2 .

\subsection{Alloy Ti-6Al-4V}

2.1.1 As-Received Ti-6Al-4V. The Ti-6Al-4V specimens are directly machined, in the $0^{\circ}$ direction, from a forged part provided by the company Techspace Aero (Fig. 1a).

The Ti-6Al-4V alloy investigated in this work is made of equiaxed primary $\alpha$ grains and secondary $\alpha$ lamellae dispersed in the $\beta$ matrix (Fig. 1b). The volume fraction of $\alpha$ phase is between 80 and $90 \%$. The transus temperature is about $995{ }^{\circ} \mathrm{C}$ (Ref 2, 21). After forging in several steps in the $\alpha+\beta$ domain, the final heat treatment consists in an annealing performed at $750{ }^{\circ} \mathrm{C}(1 \mathrm{~h})$ followed by air cooling.

2.1.2 Chemical Composition. The chemical composition from the top and bottom regions of the initial ingot (used to machine the forged component of Fig. 1a) is reported in Table 1.

The molybdenum equivalent in terms of chemical composition is defined as follows (Ref 25):

$$
\begin{aligned}
\text { wt. } \% \text { Mo.Eq. }= & 1.0(\text { wt. } \% \text { Mo })+0.66(\text { wt. } \% \mathrm{~V})+0.33(\text { wt. } \% \mathrm{~N}) \\
& +3(\text { wt. } \% \text { Fe })+3(\text { wt. } \% \mathrm{Cr})
\end{aligned}
$$

Using the above table and formula, the Mo-equivalent was estimated as equal to 3.48 .

\subsection{Ti5553 Alloy}

Ti5553 involves a large amount of $\beta$ stabilizer elements such as $\mathrm{Mo}, \mathrm{V}, \mathrm{Fe}$, and $\mathrm{Cr}$ (see chemical composition in Table 2). The transus temperature is about $860{ }^{\circ} \mathrm{C}(\operatorname{Ref} 22)$. This alloy is

Table 1 Chemical composition of alloy Ti-6Al-4V, in weight per cent (wt.\%)

\begin{tabular}{lcccccrrr}
\hline & $\mathbf{C}$ & $\mathbf{S i}$ & $\mathbf{M n}$ & $\mathbf{M o}$ & $\mathbf{A l}$ & $\mathbf{V}$ & $\mathbf{F e}$ & $\mathbf{C u}$ \\
\hline $\begin{array}{l}\text { Bottom } \\
\text { Top }\end{array}$ & 0.014 & $<0.01$ & $<0.01$ & $<0.01$ & 6.5 & 4.12 & 0.16 \\
\hline & 0.012 & $<0.01$ & $<0.01$ & $<0.01$ & 6.46 & 4.05 & 0.15 & 0.02 \\
\hline Bottom & $\mathbf{B r}$ & $\mathbf{Y}$ & $\mathbf{O}$ & $\mathbf{N}$ & $\mathbf{S n}$ & $\mathbf{C r}$ & $\mathbf{N i}$ \\
Top & $<0.001$ & $<0.01$ & $<0.001$ & 0.16 & 0.008 & $<0.01$ & $<0.1$ \\
\hline
\end{tabular}


Table 2 Chemical composition of the Ti5553 alloialy (values are in wt.\%)

\begin{tabular}{lcccccccccccc}
\hline & Mo & Zr & Fe & V & Si & Al & C & O & N & Cr & Y & H \\
\hline Bottom & 4.82 & $<0.005$ & 0.3 & 4.93 & $<0.03$ & 5.26 & 0.009 & 0.14 & 0.005 & 3.04 & $<0.001$ & 0.006 \\
Top & 4.87 & $<0.005$ & 0.3 & 4.94 & $<0.03$ & 5.33 & 0.007 & 0.14 & 0.004 & 3.05 & $<0.001$ & 0.004 \\
\hline
\end{tabular}
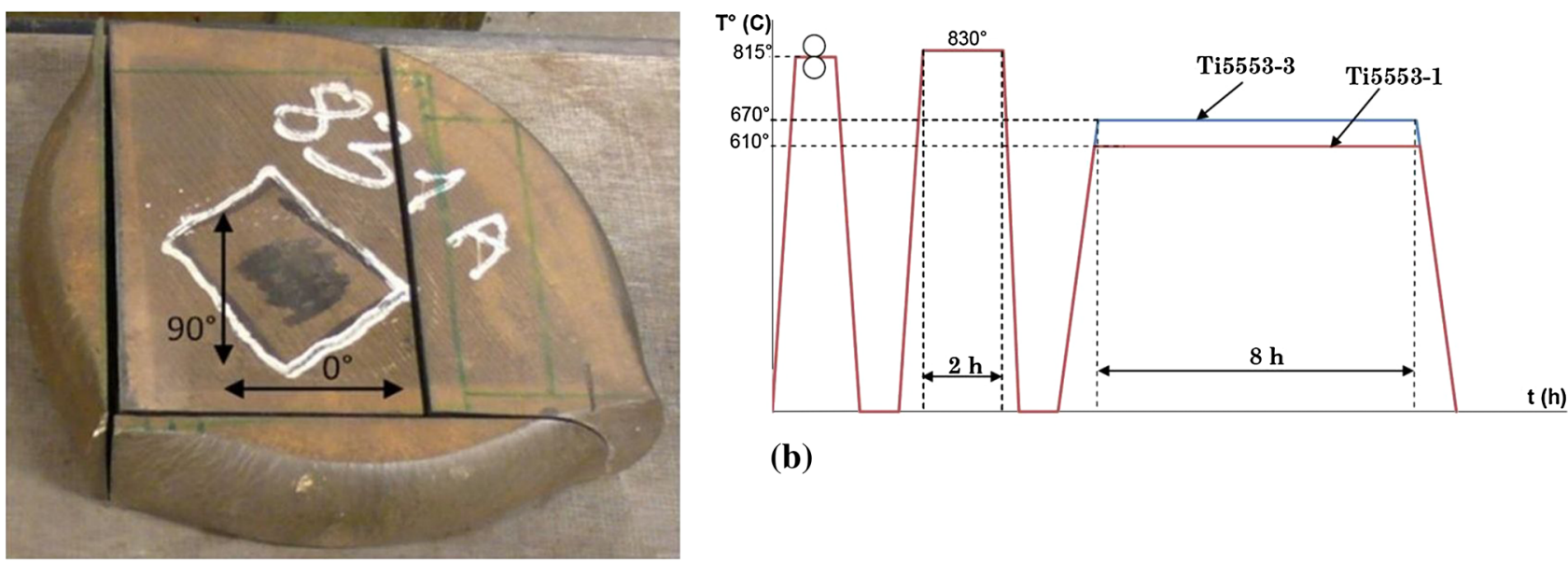

(b)

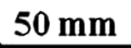

(a)

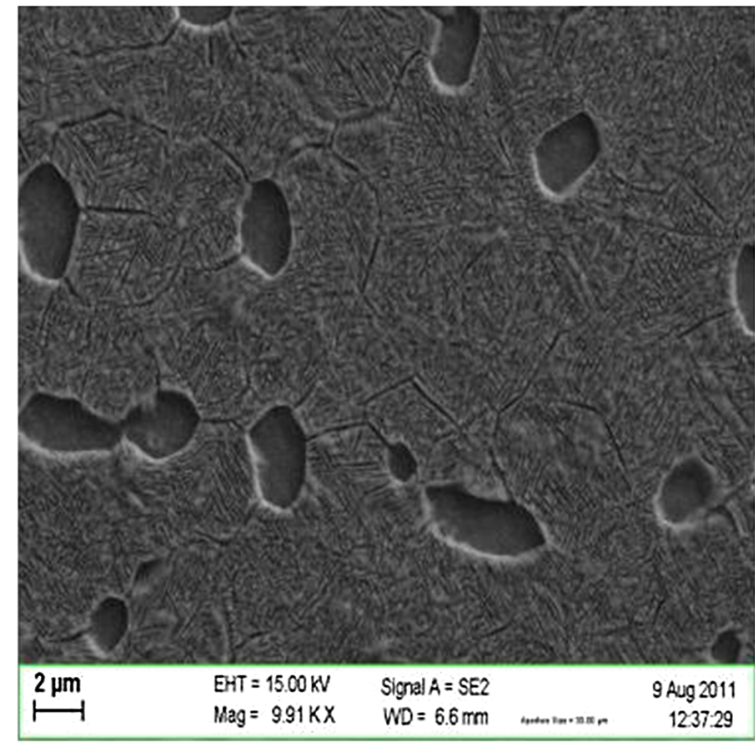

(c)

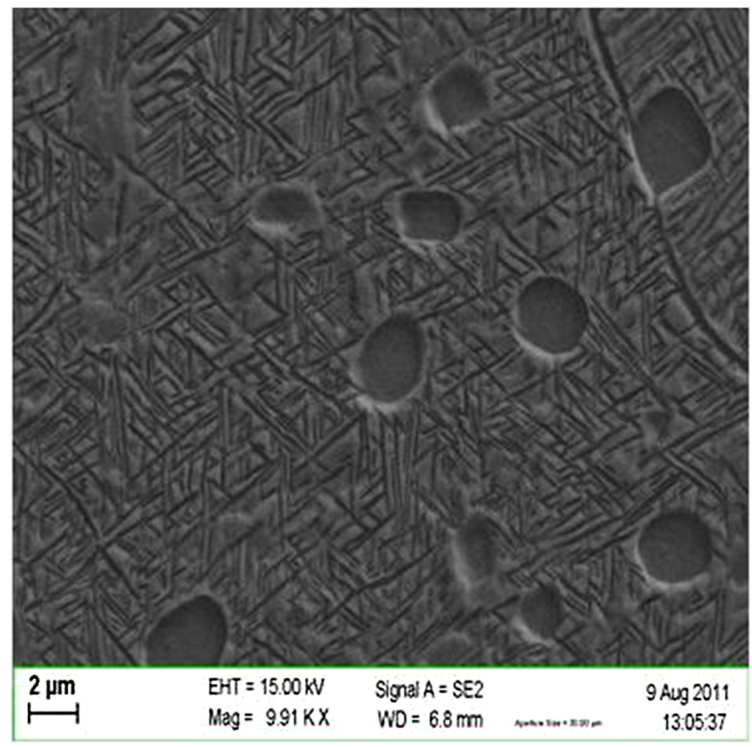

(d)

Fig. 2 Ti5553 material: (a) forged pancake, (b) final heat treatment cycle of the two microstructures, (c) scanning electron microscopy micrographs of microstructure Ti5553-1 (aging at $610^{\circ} \mathrm{C}$ ), and (d) scanning electron microscopy micrographs of microstructure Ti5553-3 (aging at $\left.670^{\circ} \mathrm{C}\right)$

highly sensitive to minute variations in the heat and thermomechanical treatments. This sensitivity has a significant impact on the microstructure as demonstrated hereafter.

The material of the study has been provided by the company Techspace Aero in the form of forged pancakes (Fig. 2a). The forging of the pancakes was performed at $815^{\circ} \mathrm{C}$ using a 2500 tons forging press. The final thickness of the pancakes is equal to $47 \mathrm{~mm}$. Based on the chemical composition (Table 2) and Eq 7, the Mo equivalent was estimated as equal to 18.18 . The specimens used to characterize the elastoviscoplastic behavior are machined in the $0^{\circ}$ direction.

The chemical composition from the top and bottom regions of the ingot is reported in Table 2. 
The final heat treatment used to generate the two Ti5553 microstructures is the following (see Fig. 2b):

- Ti5553-1: heated from room temperature up to $830{ }^{\circ} \mathrm{C}+$ hold at $830{ }^{\circ} \mathrm{C}$ during $2 \mathrm{~h}+$ air cooling + aging at $610{ }^{\circ} \mathrm{C}$ during $8 \mathrm{~h}+$ air cooling;

- Ti5553-3: heated from room temperature up to $830{ }^{\circ} \mathrm{C}+$ hold at $830{ }^{\circ} \mathrm{C}$ during $2 \mathrm{~h}+$ air cooling + aging at $670{ }^{\circ} \mathrm{C}$ during $8 \mathrm{~h}+$ air cooling.

The resulting microstructures are made of equiaxed primary $\alpha$ grains and secondary $\alpha$ needles embedded in the $\beta$ matrix. These two microstructures are thus bi-modal; the primary $\alpha$ phase involves a nodular morphology and the secondary $\alpha$ is lamellar. The volume fraction of $\alpha$ phase is about $20 \%$.

The first aging at $830{ }^{\circ} \mathrm{C}$ (Fig. 2b) is responsible for the nucleation of the $\alpha$ nodules. This aging is the same for both microstructures, explaining why there is no difference between the morphology and the size of the nodular $\alpha$ phase. The only difference between the two microstructures is related to the aging temperature. This temperature was responsible for the formation of the secondary $\alpha$ phase, which contains needles like particle shape or very small plates. The microstructure of Ti5553-1

Table 3 Young's modulus of Ti-6Al-4V and Ti5553 alloys

\begin{tabular}{lll}
\hline Alloy & \multicolumn{1}{c}{ RT } & $\mathbf{1 5 0}^{\circ} \mathbf{C}$ \\
\hline Ti5553-1, GPa & $113 \pm 7$ & $89 \pm 5$ \\
Ti5553-3, GPa & $107 \pm 8$ & $86 \pm 6$ \\
Ti-6Al-4V, GPa & $118 \pm 12$ & $94 \pm 10$ \\
\hline
\end{tabular}

shown in Fig. 2(c), is slightly finer compared to the Ti5553-3 microstructure shown in Fig. 2(d), due to a lower aging temperature $\left(610^{\circ} \mathrm{C}\right)$. Note that the presence of the secondary $\alpha$ phase is an important source of hardening in the alloy.

\section{Elastoviscoplastic Model}

In Ref 20, the elastoviscoplastic behavior of Ti5553 has been characterized and compared to the classical Ti-6Al-4V. The true stress-strain curves were determined from uniaxial tensile tests performed under different strain rates at room temperature and at $150{ }^{\circ} \mathrm{C}$. The Young's modulus of Ti-6Al-4V and Ti5553 are given in Table 3. The Poisson ratio is assumed to be independent of strain rate and temperature, and found to be close to $0.33 \pm 0.03$ for the different alloys and microstructures.

On the basis of these tensile tests, the parameters of the NortonHoff model (Ref 26, 27) were calibrated. The Norton-Hoff law, which is frequently used for Ti alloys (Ref 28, 29), writes:

$\sigma_{\text {eq }}=\exp \left(-P_{1} \varepsilon_{\text {eq }}\right) \sqrt{3} P_{2}\left(\sqrt{3} \dot{\varepsilon}_{\text {eq }}\right)^{P_{3}} \bar{\varepsilon}_{\text {eq }}^{P_{4}}$,

where $\sigma_{\text {eq }}, \varepsilon_{\text {eq }}$, and $\dot{\varepsilon}_{\text {eq }}$ are the Von Mises equivalent stress, equivalent strain, and equivalent strain rate, respectively:

$\sigma_{\mathrm{eq}}=\sqrt{\frac{3}{2} \hat{\sigma}_{i j} \hat{\sigma}_{i j}} ; \quad \dot{\varepsilon}_{\mathrm{eq}}=\sqrt{\frac{2}{3} \hat{\dot{\varepsilon}}_{i j} \hat{\dot{\varepsilon}}_{i j}} ; \quad \varepsilon_{\mathrm{eq}}=\int_{0}^{t} \overline{\dot{\varepsilon}} d t ;$

where $\hat{\sigma}_{i j}$ are the deviatoric components of the stress tensor; $\hat{\dot{\varepsilon}}_{i j}$ are the deviatoric components of the strain rate tensor; and

Table 4 Parameters of the Norton-Hoff law

\begin{tabular}{|c|c|c|c|c|c|c|c|c|}
\hline & \multicolumn{4}{|c|}{ RT } & \multicolumn{4}{|c|}{$150^{\circ}$} \\
\hline & $P_{1}$ & $P_{2}(\mathrm{MPa})$ & $P_{3}$ & $P_{4}$ & $P_{1}$ & $P_{2}(\mathrm{MPa})$ & $P_{3}$ & $P_{4}$ \\
\hline Ti5553-1 & 0.00187 & 982 & 0.006 & 0.045 & 0.0028 & 964 & 0.0015 & 0.077 \\
\hline Ti5553-3 & 0.005 & 872 & 0.0035 & 0.05 & 0.0018 & 860 & $4.8 \times 10^{-05}$ & 0.0874 \\
\hline Ti-6Al-4V & $5.210^{-05}$ & 758 & 0.0097 & 0.051 & 0.004 & 678 & 0.013 & 0.072 \\
\hline
\end{tabular}

Table 5 Effect of the strain rate and temperature on the initial yield stress $\sigma_{\mathrm{p} 0.2}$

\begin{tabular}{|c|c|c|c|c|c|c|}
\hline \multirow[b]{2}{*}{$\dot{\varepsilon}, \mathbf{s}^{-1}$} & \multicolumn{2}{|c|}{$\sigma_{\mathrm{p} 0.2}$ of Ti5553-1 } & \multicolumn{2}{|c|}{$\sigma_{\mathrm{p} 0.2}$ of Ti5553-3 } & \multicolumn{2}{|c|}{$\sigma_{p 0.2}$ of Ti-6Al-4V } \\
\hline & RT & $150{ }^{\circ} \mathrm{C}$ & RT & $150^{\circ} \mathrm{C}$ & RT & $150^{\circ} \mathrm{C}$ \\
\hline $5 \times 10^{-5}$ & $1290 \pm 10$ & $1157 \pm 28$ & $1123 \pm 15$ & $1001 \pm 20$ & $912 \pm 5$ & $738 \pm 3$ \\
\hline $2 \times 10^{-4}$ & $1336 \pm 10$ & $1158 \pm 8$ & $1144 \pm 6$ & $1007 \pm 17$ & $934 \pm 7$ & $766 \pm 10$ \\
\hline $4 \times 10^{-3}$ & $1362 \pm 9$ & $1187 \pm 8$ & $1187 \pm 18$ & $1027 \pm 8$ & $988 \pm 17$ & $806 \pm 20$ \\
\hline $10^{-2}$ & $1382 \pm 9$ & $1198 \pm 8$ & $1218 \pm 12$ & $1035 \pm 13$ & $995 \pm 2$ & $817 \pm 9$ \\
\hline
\end{tabular}

Table 6 Effect of the strain rate and temperature on the ultimate stress $\sigma_{u}$

\begin{tabular}{|c|c|c|c|c|c|c|}
\hline \multirow[b]{2}{*}{$\dot{\varepsilon}, \mathbf{s}^{-1}$} & \multicolumn{2}{|c|}{$\sigma_{u}$ of Ti5553-1 } & \multicolumn{2}{|c|}{$\sigma_{\mathrm{u}}$ of Ti5553-3 } & \multicolumn{2}{|c|}{$\sigma_{u}$ of Ti-6Al-4V } \\
\hline & RT & $150^{\circ} \mathrm{C}$ & RT & $150^{\circ} \mathrm{C}$ & RT & $150^{\circ} \mathrm{C}$ \\
\hline $5 \times 10^{-5}$ & $1375 \pm 14$ & $1303 \pm 20$ & $1260 \pm 30$ & $1172 \pm 25$ & $1046 \pm 3$ & $880 \pm 2$ \\
\hline $2 \times 10^{-4}$ & $1390 \pm 24$ & $1300 \pm 17$ & $1268 \pm 46$ & $1179 \pm 5$ & $1062 \pm 10$ & $872 \pm 35$ \\
\hline $4 \times 10^{-3}$ & $1404 \pm 15$ & $1314 \pm 8$ & $1278 \pm 25$ & $1183 \pm 5$ & $1044 \pm 13$ & $911 \pm 15$ \\
\hline $10^{-2}$ & $1430 \pm 23$ & $1312 \pm 17$ & $1272 \pm 20$ & $1176 \pm 13$ & $1060 \pm 6$ & $921 \pm 14$ \\
\hline
\end{tabular}



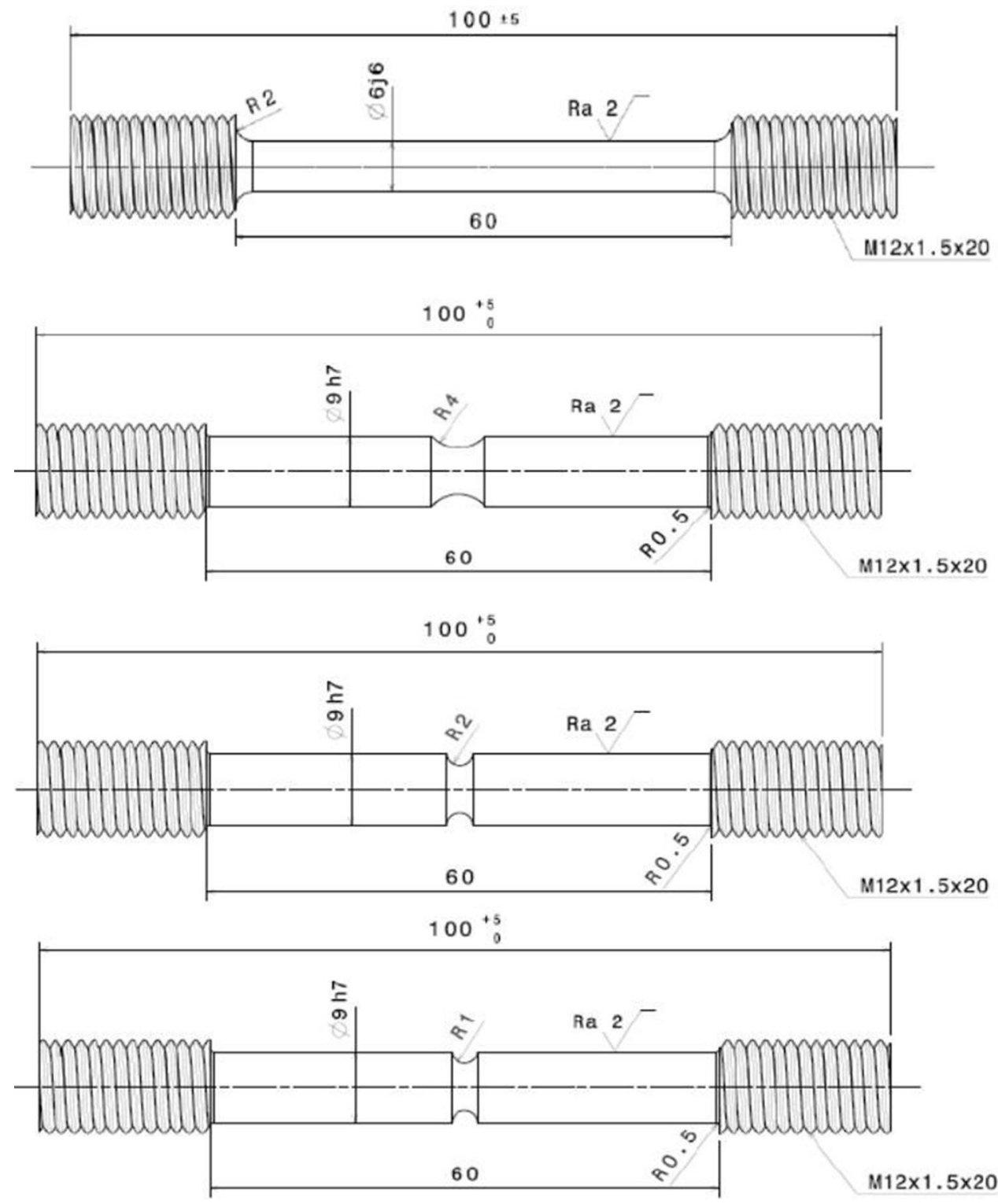

Fig. 3 Geometry of the smooth and notched specimens (dimensions in $\mathrm{mm}$ )

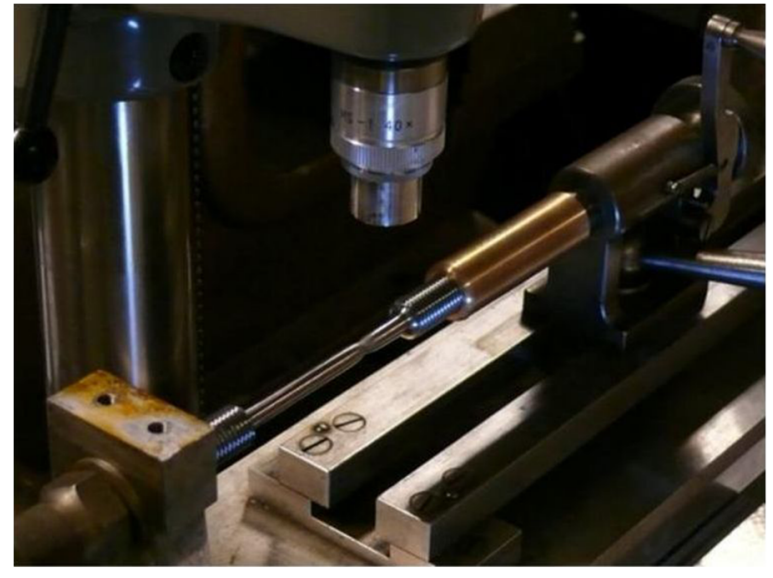

(a)

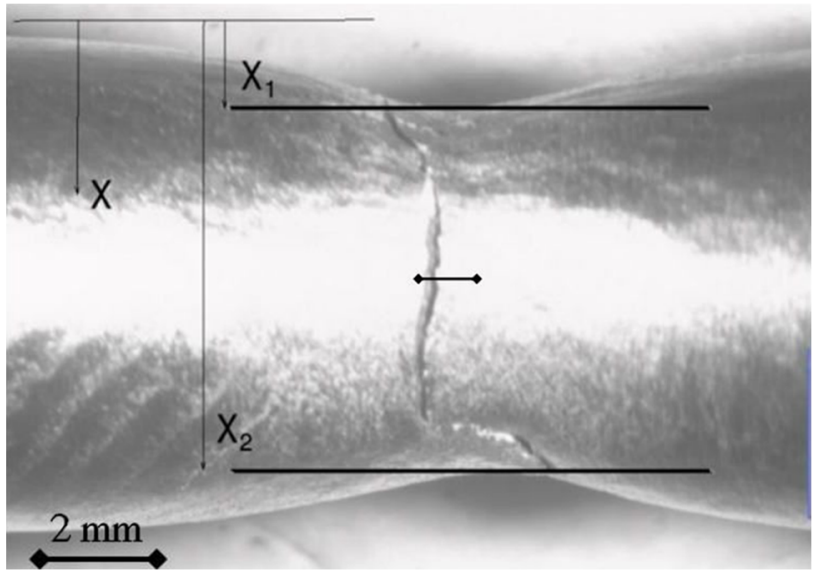

(b)

Fig. 4 Measurement of the cross-section area after fracture: (a) experimental setup and (b) optical micrograph of a reconstituted specimen 
$P_{1}, P_{2}, P_{3}$, and $P_{4}$ are a softening parameter, a scaling factor, the strain rate sensitivity exponent, and the hardening exponent, respectively.

The $\mathrm{J}_{2}$ viscoplastic theory is based on the following set of equations ( $\operatorname{Ref} 28)$ :

$\hat{\dot{\varepsilon}}_{i j}=\frac{3 \dot{\varepsilon}_{\mathrm{eq}}}{2 \sigma_{\mathrm{eq}}} \hat{\sigma}_{i j}$.

Hence, the relationship between the deviatoric stress, $\hat{\sigma}_{i j}$, and the deviatoric strain rate, $\hat{\dot{\varepsilon}}_{i j}$, tensors writes for a Norton-Hoff hardening law:

$\hat{\sigma}_{i j}=2 P_{2}\left(\sqrt{3} \dot{\varepsilon}_{\mathrm{eq}}\right)^{P_{3}-1}\left(\varepsilon_{\mathrm{eq}}\right)^{P_{4}} \exp \left(-P_{1} \varepsilon_{\mathrm{eq}}\right) \hat{\dot{\varepsilon}}_{i j}$.

The viscoplastic parameters $P_{1}, P_{2}, P_{3}$, and $P_{3}$ determined from the calibration procedure at RT and $150{ }^{\circ} \mathrm{C}$ are given in Table 4 .

As demonstrated in Tables 5 and 6, the strength of Ti5553 is $20-40 \%$ higher than the strength of Ti- $6 \mathrm{Al}-4 \mathrm{~V}$. Ti5553 consti-

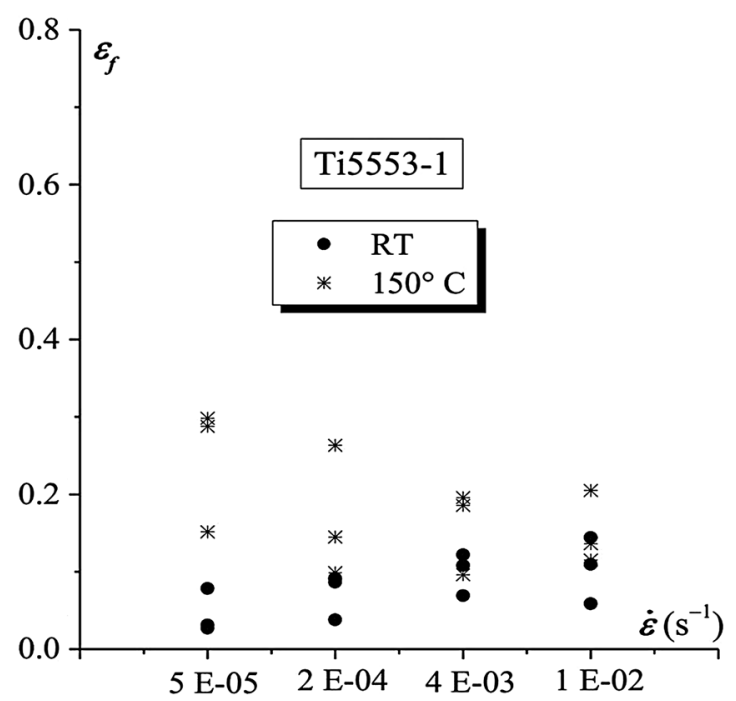

(a)

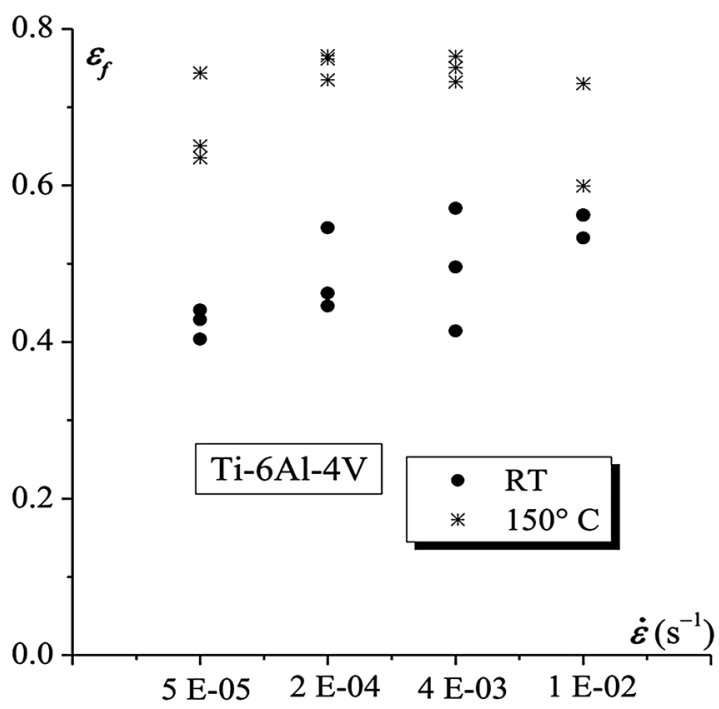

(c) applications.

(b)

tutes thus a promising candidate for advanced structural

The elastic and plastic initial anisotropy of both alloys has been investigated by combining compression on cylinders with elliptical sections, uniaxial tensile tests in different material directions, plane strain, and shear tests, see Ref 20. The conclusion is that the initial anisotropy of the different alloys is weak which justifies modeling the mechanical behavior with an isotropic version of the Norton-Hoff model.

\section{Damage Analysis Using Cylindrical Notched Round Specimens}

\subsection{Description of the Mechanical Tests}

Tensile tests were performed at room temperature (RT) and at $150{ }^{\circ} \mathrm{C}$ on cylindrical notched round bars with three different

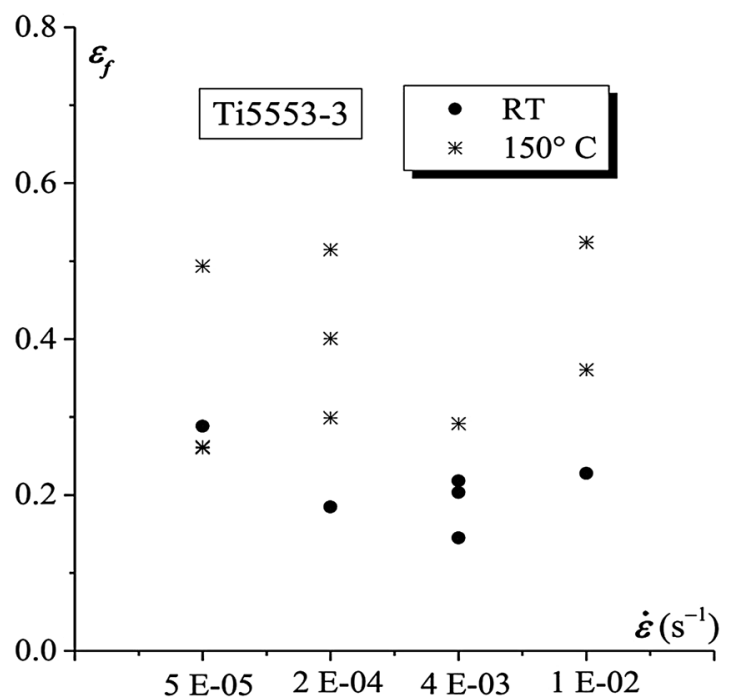




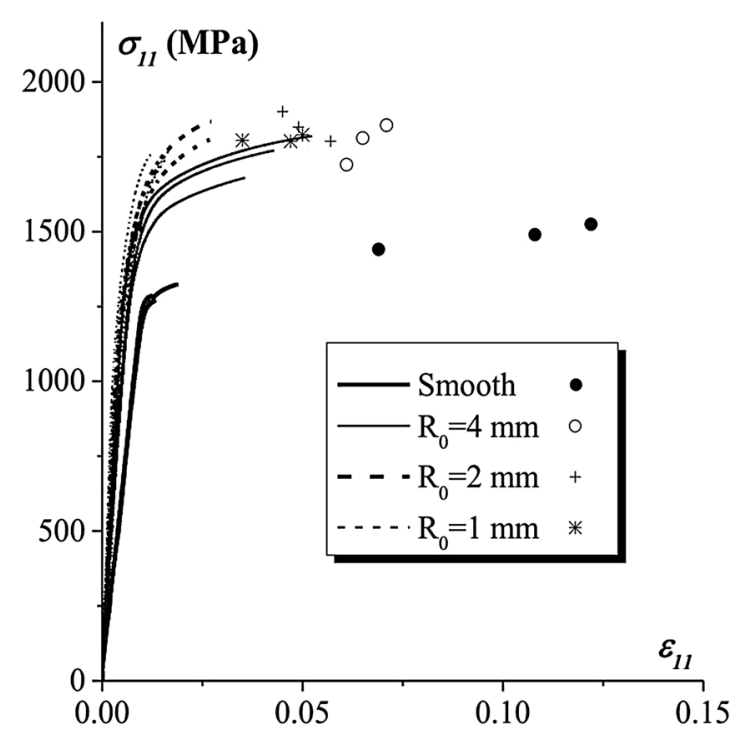

(a)

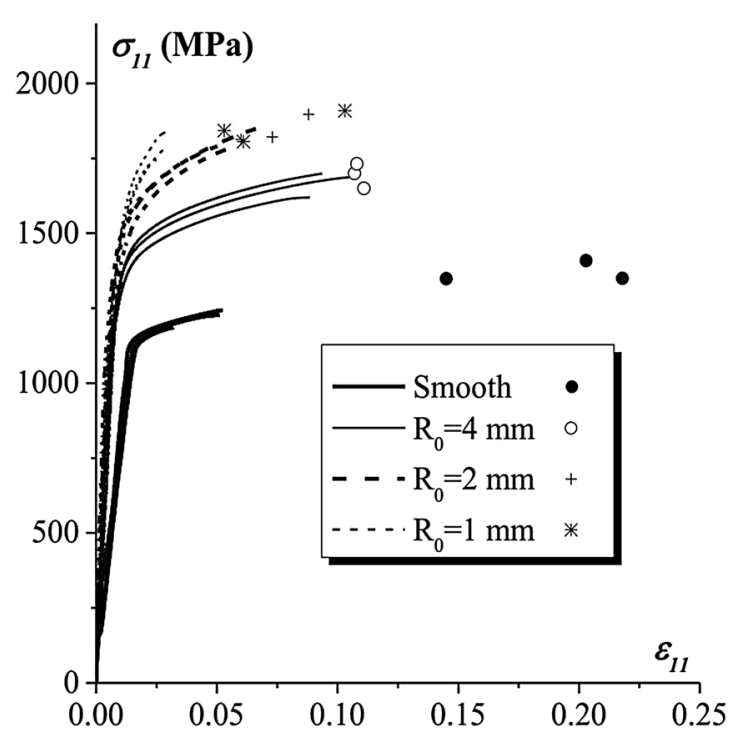

(b)

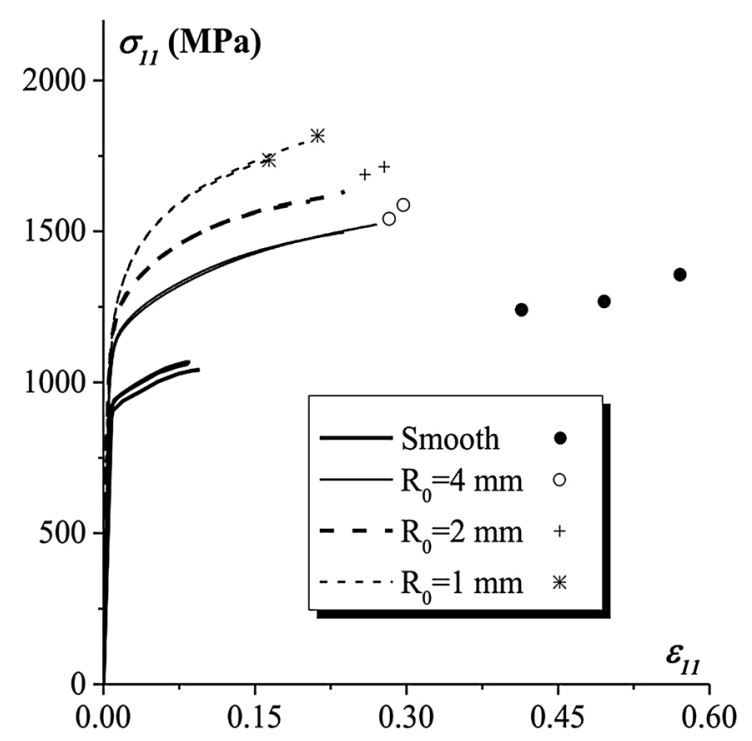

(c)

Fig. 6 Overall experimental axial stress as a function of the axial strain for the smooth and notched round specimens tested at room temperature ( 3 or 2 tests for each conditions): (a) Ti5553-1, (b) Ti5553-3, and (c) Ti-6Al-4V

notch root initial radii $R_{0}=1,2$, and $4 \mathrm{~mm}$ (see Fig. 3). The initial diameter of the minimum cross-section was kept constant, equal to $6 \mathrm{~mm}$ for all test specimens. The different notches induce different levels of stress triaxiality (the stress triaxiality $T$ is defined as the ratio between the hydrostatic stress $\sigma_{\mathrm{h}}$ over the von Mises equivalent stress $\sigma_{\text {eq }}$, i.e. $T=\sigma_{\mathrm{h}} / \sigma_{\mathrm{eq}}$ ). Three duplicate tests were conducted for each condition of temperature, notch radius, alloy, and heat treatment. The applied load, crosshead displacement, and reduction of diameter of the minimum cross-section were continuously recorded during the test.

The ductility of the material, defined by the true average fracture strain $\varepsilon_{\mathrm{f}}$, is calculated as:

$$
\varepsilon_{\mathrm{f}}=\ln \left(\frac{S_{0}}{S_{\mathrm{f}}}\right)
$$

where $S_{0}$ and $S_{\mathrm{f}}$ are the initial and final cross-section areas, respectively. The initial value $S_{0}$ was accurately measured prior to testing.

The minimum cross-section area after fracture $S_{\mathrm{f}}$ is determined using optical microscopy micrographs, after reconstitution of the broken specimen, see Fig. 4(a). The cross-section is assumed to be elliptical. The minor and major diameters are identified visually, and the corresponding coordinates, $X_{1}$ and $X_{2}$ (see Fig. 4b), are measured. The difference $X_{2}-X_{1}$ provides 
the magnitude of the diameter. The cross-section is computed by means of the equation of an ellipse.

Note that this approach assumes an homogenous strain distribution within the minimum cross-section. This assumption is not very accurate. Indeed, the true local fracture strain which corresponds to the initiation of a crack (usually in the center of the specimen) is slightly smaller than the average value $\varepsilon_{\mathrm{f}}$ (see, e.g., Ref 30). Nevertheless, $\varepsilon_{\mathrm{f}}$ provides a relevant index to rank the ductility of materials (see Fig. 5) and a global calibration parameter for damage modeling.

\subsection{Experimental Results}

4.2.1 Effect of the Strain Rate and Temperature on the Fracture Strain. Figure 5 shows the variation of the fracture strain corresponding to uniaxial tension conditions (i.e., no notch) as a function of strain rate for the three different materials and the two test temperatures. In Ref 20, it was shown that the strength of the $\mathrm{Ti}$ alloys varies with strain rate. Nevertheless, the strain rate effect on $\varepsilon_{f}$ is rather small except for the tests at room temperature on Ti5553-1. Note that several studies have addressed the effect of the strain rate on ductility (Ref 19, 31-33). The fracture strain sometimes decreases with increasing strain rate due to an increase of the strength which, in turn, induces earlier void nucleation, while it sometimes increases with increasing strain rate due to local heating. Figure 5 shows that the ductility of both Ti5553 and Ti-6Al-4V increases with increasing temperature. This result is consistent with other experimental studies on Ti alloys (Ref 34-36). We attribute the limited increase of fracture strain with strain rate to

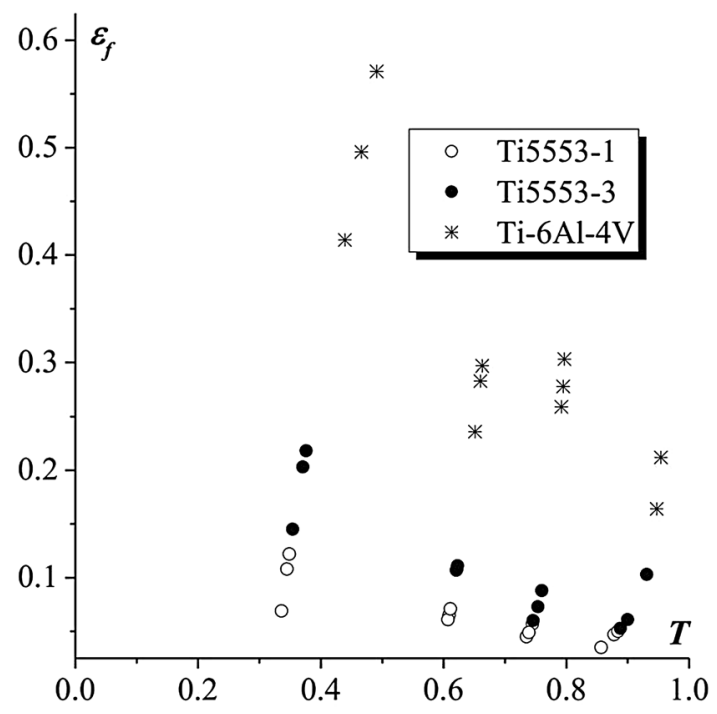

Fig. 7 Variation of the fracture strain as a function of the stress triaxiality at RT the increase of temperature at higher strain rates promoted by the low thermal conductivity of Ti. Note that, finally, the dispersion on $\varepsilon_{\mathrm{f}}$ at the same strain rate is sometimes quite large. This dispersion is presumably due to mesoscale microstructure heterogeneities such as macrozones. Further investigations are required in order to better understand and rationalize the origin of this dispersion.

4.2.2 Effect of Stress Triaxiality on Fracture. The RT overall experimental axial stress versus axial strain for smooth and notched round specimens tests are compared in Fig. 6 (three curves for each radius corresponding to the three repetitions). The average stress is calculated by dividing the experimental force by the current minimum cross-section area. The curves corresponding to uniaxial tension are interrupted at maximum load. The corresponding fracture points are indicated in the figures as well. The stress at fracture is calculated as the force just before fracture divided by the measured area at fracture, and the corresponding strain is calculated using Eq 6. Note that the apparent elastic modulus (the slope of the stressstrain curve) increases with increasing stress triaxiality which can be easily explained by application of Hooke's law in the presence of transverse stress.

Many experimental investigations have demonstrated that the fracture strain (see Eq 6) strongly depends on stress triaxiality (Ref 37-41). Two methodologies are typically used to evaluate the stress triaxiality: the first one is analytical and is based on the Bridgman analysis (Ref 42) and the second is numerical and based on FE simulations. The latter is more accurate and more realistic than the Bridgman formula, and it is thus used here for the notched specimens. The fracture strain $\varepsilon_{\mathrm{f}}$ is plotted in Fig. 7 (see also Table 7) as a function of the average stress triaxiality (computed over the minimum section just before rupture) numerically predicted by using Lagamine FE code (Ref 43).

The connection between fracture strain $\varepsilon_{\mathrm{f}}$ and stress triaxiality $T$ for the different specimen geometries is given in Table 7.

As expected, the ductility heavily depends on stress triaxiality, see also, e.g., Ref 13, 43.

The fracture strain of Ti-6Al-4V is significantly higher than for both Ti5553 microstructures. The lower ductility ofTi5553 can be empirically correlated to the Mo-equivalent, as explained in Ref 20, 44. The alloy Ti5553 involves a Mo-equivalent value almost five times larger than in the Ti-6Al-4V alloy. Ti5553-3 is almost two times more ductile than Ti5553-1. The model developed in next section provides additional insights about the origins of the differences in fracture strain through a direct link with the underlying damage mechanisms.

\subsection{Damage Model}

Several studies in the literature (Ref 45-47) show that the Ti alloys often fail by a ductile fracture mechanism. A damage

Table 7 Connection between the initial notch radius $R_{0}$, the fracture strain $\varepsilon_{\mathrm{f}}$, and the stress triaxiality $T$ at RT

\begin{tabular}{|c|c|c|c|c|c|c|}
\hline \multirow[b]{2}{*}{$R_{0}, \mathrm{~mm}$} & \multicolumn{2}{|c|}{ Ti5553-1 } & \multicolumn{2}{|c|}{ Ti5553-3 } & \multicolumn{2}{|c|}{ Ti-6Al-4V } \\
\hline & $\varepsilon_{\mathrm{f}}$ & $T$ & $\varepsilon_{\mathrm{f}}$ & $T$ & $\varepsilon_{\mathrm{f}}$ & $T$ \\
\hline$\infty$ & $0.1 \pm 0.03$ & $0.34 \pm 0.005$ & $0.19 \pm 0.04$ & $0.37 \pm 0.01$ & $0.49 \pm 0.08$ & $0.47 \pm 0.025$ \\
\hline 4 & $0.06 \pm 0.005$ & $0.61 \pm 0.005$ & $0.11 \pm 0.005$ & $0.62 \pm 0.005$ & $0.26 \pm 0.025$ & $0.66 \pm 0.005$ \\
\hline 2 & $0.050 \pm 0.005$ & $0.74 \pm 0.005$ & $0.07 \pm 0.015$ & $0.75 \pm 0.005$ & $0.28 \pm 0.020$ & $0.79 \pm 0.005$ \\
\hline 1 & $0.05 \pm 0.01$ & $0.87 \pm 0.015$ & $0.07 \pm 0.025$ & $0.91 \pm 0.020$ & $0.19 \pm 0.035$ & $0.95 \pm 0.005$ \\
\hline
\end{tabular}




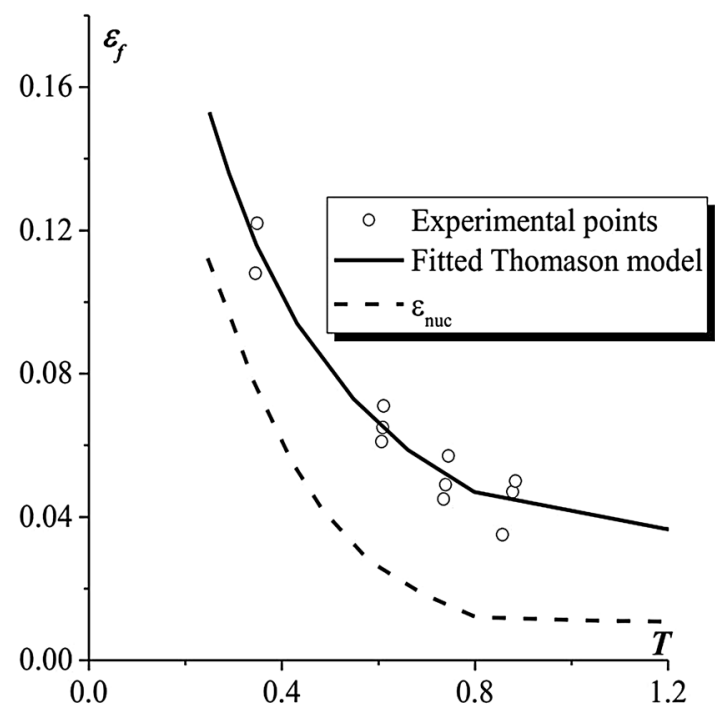

(a)

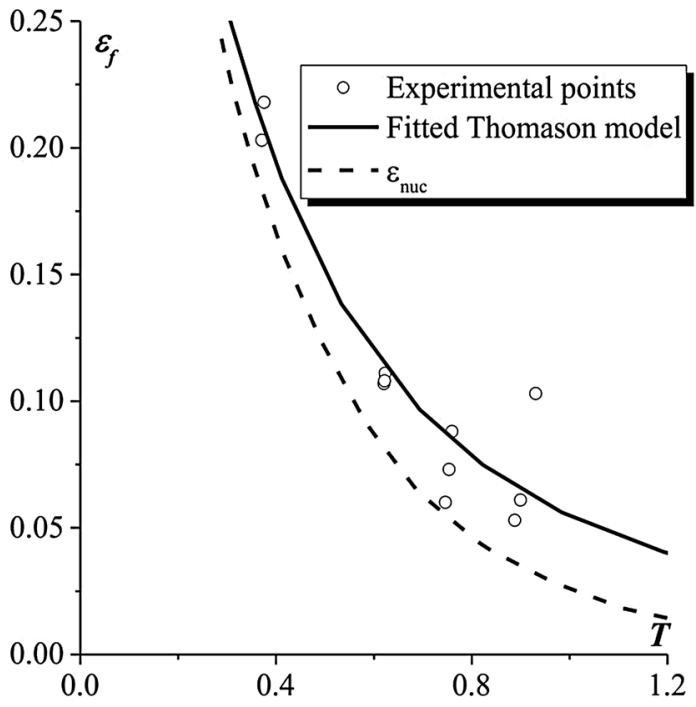

(b)

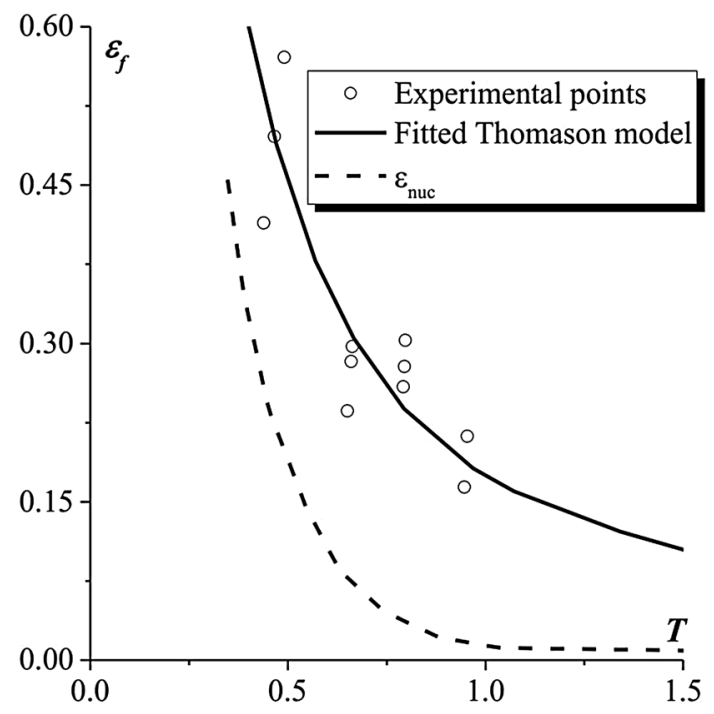

(c)

Fig. 8 Comparison between model predictions and experimental results in terms of the variation of fracture strain with average stress triaxiality: (a) Ti5553-1 at RT, (b) Ti5553-3 at RT, and (c) Ti-6Al-4V at RT. The variation of $\varepsilon_{\text {nuc }}$ is also provided

Table 8 Parameters of the damage model calibrated for the different alloys and microstructures

\begin{tabular}{lccc}
\hline & $\chi_{\mathbf{0}}$ & $\boldsymbol{\sigma}_{\text {nuc }}, \mathbf{M P a}$ & $\boldsymbol{k}$ \\
\hline Ti-6Al-4V & 0.44 & 1691 & 2.21 \\
Ti5553-1 & 0.78 & 1974 & 4.26 \\
Ti5553-3 & 0.78 & 2270 & 4.57 \\
\hline
\end{tabular}

model must ideally integrate all the relevant physical phenomena in order to allow relating the microstructure to the damage and fracture resistance. More precisely, in most metals, ductile fracture proceeds by the nucleation of voids through decohesion or fracture of second phase particles, followed by the growth of the voids, involving also an evolution of the shape, up to a point where plastic deformation starts localizing in the ligament between the voids. This last step is the onset of the void coalescence mechanism. After the onset of coalescence, coalescence by impingement of the voids follows quickly leading to the generation of a microcrack that can then propagate in the entire material. One can thus consider that the onset of coalescence constitutes the physical failure condition, being a good indicator of the point at which a material element looses its load carrying capacity (see Ref 30, 48) for more detailed discussions). An attempt is made in the present study to use a micromechanics based damage model based on the Beremin's nucleation condition (Ref 49), on the Rice and Tracey model (Ref 13) for the dilatational part of the growth of the voids and on the Thomason coalescence criterion (Ref 50). These models are supplemented by evolution laws for the void aspect ratio and for the void spacing ratio as proposed in Ref 51 for initially penny shaped cavities. 
Beremin's void nucleation criterion (Ref 49) writes

$\sigma_{\text {nuc }}=\sigma_{\text {princ }}^{\max }+k\left(\sigma_{\mathrm{eq}}-\sigma_{0}\right)$,

where $\sigma_{\text {princ }}^{\max }$ is the maximum principal stress; $k$ is a function of the particle shape and of the loading direction; $\sigma_{\text {eq }}$ is the equivalent Von Mises stress; and $\sigma_{0}$ is the initial yield stress.

The Thomason coalescence condition is expressed by

$$
\left(\frac{\sigma_{\text {princ }}^{\max }}{\sigma_{\text {eq }}}\right) \frac{1}{\left(1-\chi^{2}\right)}=\alpha\left(\frac{1-\chi}{\chi W}\right)^{2}+1.24 \sqrt{\frac{1}{\chi}} \text {, }
$$

where $W$ is the current void aspect ratio estimated using (see Ref 51):

$W=\lambda_{0} \frac{\exp \left(\varepsilon-\varepsilon_{\text {nuc }}\right)-1}{\exp \left(\left(\varepsilon-\varepsilon_{\text {nuc }}\right) / 2\right)}$

and $\chi$ is the current void spacing (see Ref 51)

$\chi=\chi_{0} \frac{\exp (\varepsilon / 2)\left((C-1) \exp \left[C\left(\varepsilon-\varepsilon_{\text {nuc }}\right)\right]+1\right)}{C}$

with

$C=0.427 \exp \left(\frac{3}{2} T\right)$

and where $\varepsilon$ is the maximum principal strain; $\varepsilon_{\text {nuc }}$ is the maximum principal strain required to nucleate a cavity (threshold value). This strain is determined using Beremin's condition as explained later; $\lambda_{0}$ is a factor describing the degree of anisotropy in the void distribution; $\chi_{0}$ is the initial relative void spacing; $C$ is a variable dependent on the stress triaxiality $T$ (see Eq 11). The expression of $C$ has been assessed by several authors (e.g., Ref 52) and gives satisfactory predictions as long as the void volume fraction is sufficiently small, which is the basic underlying assumption of the Rice and Tracey analysis dealing with isolated void (Ref 13). The factor ' 0.427 ' appearing in the expression of $C$, instead of ' 0.283 ' as initially proposed by Rice and Tracey, has been re-computed by Huang (Ref 53); see also a recent work based on tomography measurements for a re-assessment of this model in the case of Ti-6Al-4V (Ref 54). $\alpha$ is a fitting parameter related to the strain hardening exponent. The parameter has been fitted as a function of the average value of the strain hardening exponent $n: \alpha(n)=0.1+0.22 n+4.8 n^{2}$ (Ref 55), see Ref 56 for alternative approaches.

In the case of axisymmetric loading and constant stress triaxiality, the following equation applies:

$\frac{\sigma_{\mathrm{princ}}^{\max }}{\sigma_{\mathrm{eq}}}=T+\frac{2}{3}$,

leading to the simplified expression for the coalescence criterion:

$\frac{T+(2 / 3)}{\left(1-\chi^{2}\right)}=\alpha\left(\frac{1-\chi}{\chi W}\right)^{2}+1.24 \sqrt{\frac{1}{\chi}}$.

For a given stress triaxiality $T$, coalescence occurs for a strain $\varepsilon=\varepsilon_{\mathrm{f}}$ such that Eq 13 is fulfilled. We thus assume that fracture corresponds to the onset of coalescence (see Ref 57 for a discussion about the validity of this assumption).

The parameter $\varepsilon_{\text {nuc }}$ (which appears in the expression of $\chi$ and $W$ ) is determined via the axisymmetric loading assumption under constant stress triaxiality in two steps. First, Eq 7 and 12 are combined as

$\sigma_{\mathrm{eq}}\left(\varepsilon_{\mathrm{nuc}}\right)=\frac{\sigma_{\mathrm{nuc}}+k \sigma_{0}}{k+T+2 / 3}$

Then the function $\varepsilon_{\text {nuc }}\left(\sigma_{\mathrm{e}}\right)$ is determined on the basis of a Newton-Raphson procedure based on the Norton-Hoff law $\sigma(\varepsilon)$ developed in section 3. In this fitting procedure, the strain rate is assumed to be equal to $0.001 \mathrm{~s}^{-1}$. This value corresponds to the mean strain rate in the center of the notched specimens as determined by the FE simulations.

\subsection{Calibration of the Damage Law}

The adopted damage model is defined by four parameters $(k$, $\left.\lambda_{0}, \chi_{0}, \sigma_{\text {nuc }}\right)$ in addition to the hardening law, and is dependent on two variables: the strain $\varepsilon$ in the tensile direction (elastic strains are neglected) and the stress triaxiality $T$. In order to simplify the calibration procedure, the parameter $\lambda_{0}$ has been fixed equal to one which implies an initial isotropic distribution of voids. The other parameters $\left(k, \chi_{0}, \sigma_{\text {nuc }}\right)$ are calibrated from the experimental results $\varepsilon_{\mathrm{f}}=\mathrm{f}(T)$ of Fig. 7. The calibration procedure is based on the $l-b f g s-b$ optimization algorithm standing for "limitedmemory Broyden-Fletcher-Goldfarb-Shanno algorithm." For more details about this algorithm, see (Ref 58-61). The calibration procedure turned out to have several shortcomings which are ultimately related to the complexity of the model:

- The stress triaxiality is assumed to be constant during the test (which is not exactly true in the practice).

- The solution is often not unique, due to the large number of parameters to be calibrated.

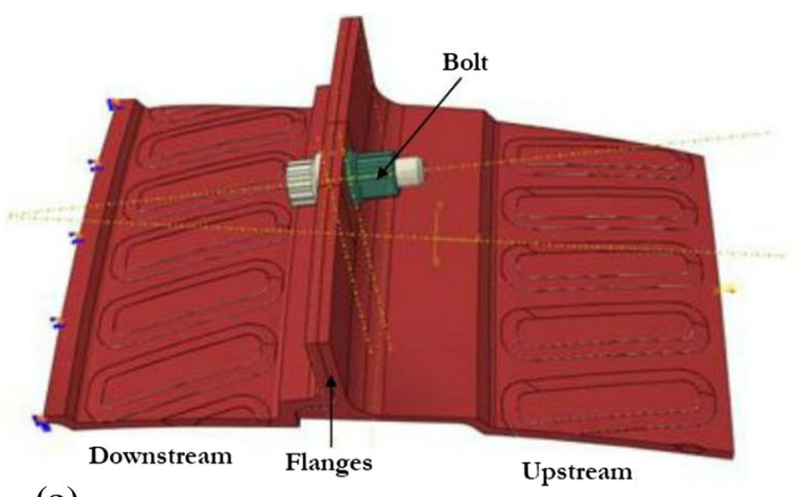

(a)

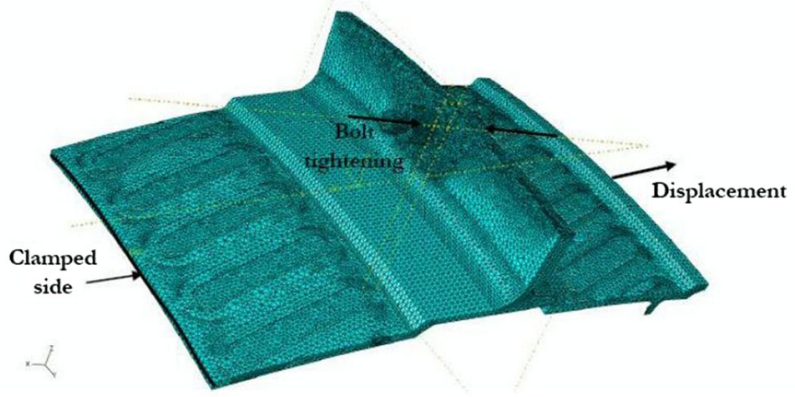

(b)

Fig. 9 (a) Geometric description of the studied system, (b) mesh, boundary conditions and loadings 


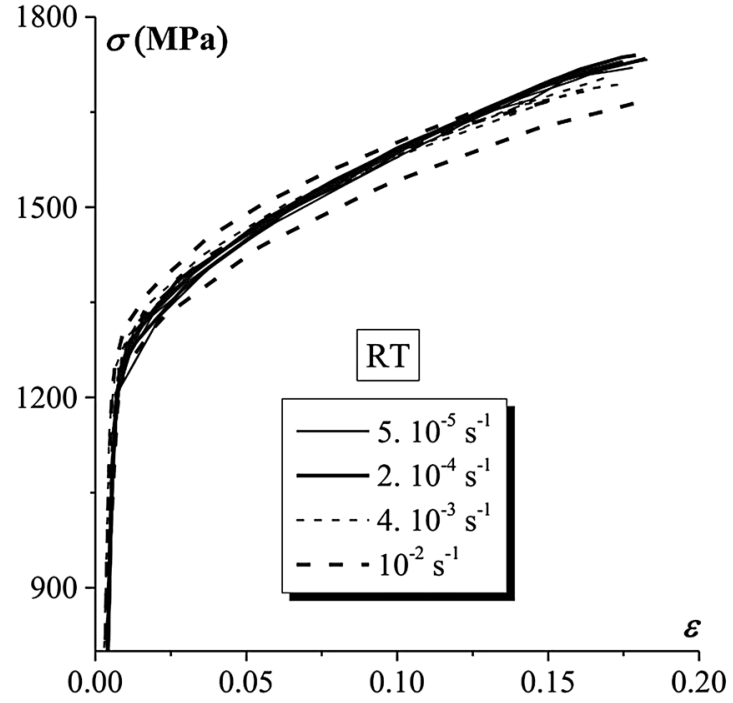

(a)

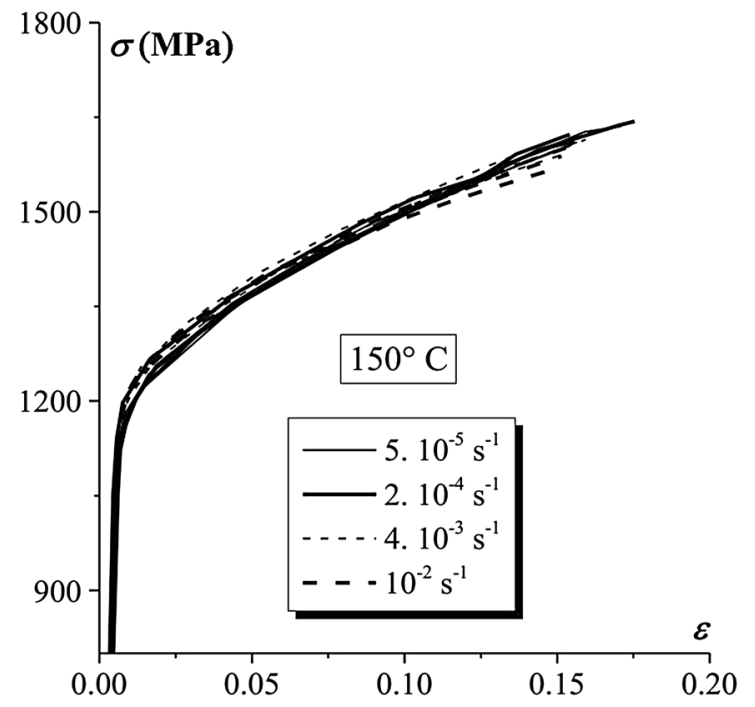

(b)

Fig. 10 True stress-true strain response of Inconel 718 alloy at different strain rates (expressed in $\mathrm{s}^{-1}$ ) and temperatures: (a) at RT and (b) at $150{ }^{\circ} \mathrm{C}$

Table 9 Calibrated mechanical parameters of Inconel 718 alloy: elasticity and parameters of the Norton-Hoff viscoplastic law

\begin{tabular}{lcccccc}
\hline & $\boldsymbol{E}, \mathbf{G P a}$ & $\boldsymbol{v}$ & $\boldsymbol{P}_{\mathbf{1}}$ & $\boldsymbol{P}_{\mathbf{2}}, \mathbf{M P a}$ & $\boldsymbol{P}_{\mathbf{3}}$ & $\boldsymbol{P}_{\mathbf{4}}$ \\
\hline $\mathrm{RT}$ & 212 & 0.35 & $5.27 \times 10^{-5}$ & 1187.97 & $5.868 \times 10^{-7}$ \\
$150{ }^{\circ} \mathrm{C}$ & 212 & 0.35 & 0.002 & 1125.73 & 0.1112 \\
\hline
\end{tabular}

- The damage model is a micromechanics based model. However, the parameters are calibrated on the basis of macroscopic tests by inverse modeling.

- Perfect solutions in a calibration procedure involving only $R_{0}=2$ and $R_{0}=4$ test conditions sometimes lead to poor predictions for the other tests (smooth samples and $R_{0}=1$ samples).

The results of the calibration are presented in Fig. 8 along with the experimental measurements, and the corresponding data are summarized in Table 8.

The curves present the best fit of all experimental data in the least square sense by the damage model.

If we assume that the premises of the model are correct, the results presented in Fig. 8 indicate that fracture is dominated by the void nucleation stage in Ti5553-3 at all stress triaxiality (i.e., fracture rapidly follows void nucleation). Ti5553-3 and Ti-6Al-4V involves a more extended void growth stage, especially at high stress triaxiality. The value of $\chi_{0}$ can be qualitatively related to the relative spacing of the nearest neighbors $\alpha$ nodules (see Fig. $2 \mathrm{c}$ and d). Note also that in Ref 54, 62, in situ 3D tomography tests on smooth bars of Ti$6 \mathrm{Al}-4 \mathrm{~V}$ show the first occurrences of void nucleation events at a strain of $\sim 0.3$ in excellent agreement with the inverse calibration performed here. The origin of the better resistance to void nucleation in the microstructure Ti5553-3 is an important finding. This is an example of microstructure engineering where failure has been postponed while not compromising on strength. Further investigation is needed to elucidate why the
Table 10 Effect of the temperature on the yield stress $\sigma_{\mathrm{p} 0.2}$ and the ultimate stress $\sigma_{\mathrm{u}}$ of Inconel 718

\begin{tabular}{lcc}
\hline & RT & $\mathbf{1 5 0}^{\circ} \mathbf{C}$ \\
\hline$\sigma_{\mathrm{p} 0.2}(\mathrm{MPa})$ & 1240 & 1140 \\
$\sigma_{\mathrm{u}}(\mathrm{MPa})$ & 1680 & 1584 \\
\hline
\end{tabular}

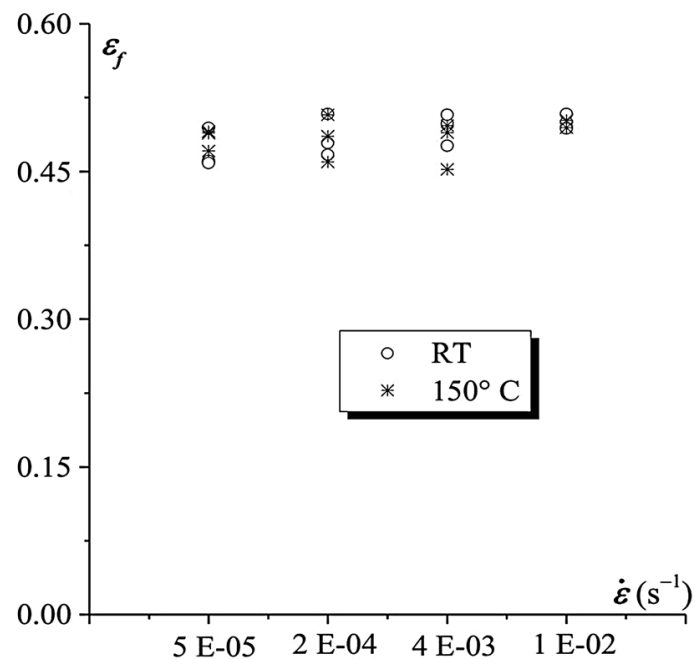

Fig. 11 Effect of strain rate and of temperature on fracture strain in Inconel 718 
coarser Ti5553-3 microstructure (compared to the Ti5553-1) is beneficial. It might have to do with lower local stress concentration promoted by a larger length scale.

\section{Application to a Bolted Sector Component}

The viscoplastic model based on the Norton-Hoff law calibrated for each material over a wide range of strains and strain rates is combined to the damage model presented in section 4 to analyze the mechanical behavior of an aircraft engine stator manufactured by the company Techspace Aero. The aim of the simulations is to compare the potential of the Ti5553 alloy compared to the Ti-6Al-4V in an industrial context.

The component of interest is composed of two sectors of an aircraft engine stator (downstream and upstream) attached together by bolted flanges as depicted in Fig. 9(a). The bolted flanges are made of Inconel 718, and the sectors are made of Ti-6Al-4V in the current design. There are three main objectives in this application:

- to validate the Norton-Hoff model previously calibrated on the Ti-6Al-4V alloy by comparing the results of the experimental tests performed on a real aircraft engine stator (in the M\&S laboratory in ULg) with the numerical predictions, see section 5.3.

- to use the uncoupled damage model presented and calibrated in section 4 to predict the damage limit of the aircraft engine stators, see section 5.4.

\subsection{Mechanical Behavior of Inconel 718 Alloy}

The bolts are made of an Inconel 718 alloy. The mechanical properties of this material have been obtained using uniaxial tensile tests at four strain rates $\left(5 \times 10^{-5}, 2 \times 10^{-4}, 4 \times 10^{-3}\right.$, and $10^{-2} \mathrm{~s}^{-1}$ ) and at two temperatures (RT and $150{ }^{\circ} \mathrm{C}$ ). Three tests were performed for each strain rate and each temperature using the same geometry and dimensions as Fig. 3. Figure 10 shows that the dispersion in the stress-strain response of this alloy is small and that there is no strain rate effect. The elasticity constants and the Norton-Hoff parameters have been calibrated (see Table 9) using the same calibration procedure as applied in Ref 20 to the Ti alloys. The strength of the Inconel 718 alloy is not as sensitive to temperature as the Ti alloys.

Table 10 gathers the yield stress $\sigma_{\mathrm{p} 0.2}$ (experimentally measured at $0.2 \%$ of plastic strain) and the true ultimate stress $\sigma_{\mathrm{u}}$ at RT and at $150{ }^{\circ} \mathrm{C}$. Only one value of $\sigma_{\mathrm{p} 0.2}$ and $\sigma_{\mathrm{u}}$ is taken by temperature, independent of strain rate.

Figure 11 shows the dependence of the fracture strain on strain rate and on temperature in Inconel 718.

The ductility of Inconel 718 is higher than the ductility of the Ti alloys studied in this work (Ti-6Al-4V and Ti5553). The ductility of Inconel 718 is independent of strain rate and of temperature. Contrarily to the Ti alloys, the dispersion between the different fracture strains $\varepsilon_{\mathrm{f}}$ is very small. Indeed, the minimum and the maximum values of $\varepsilon_{\mathrm{f}}$ are, respectively, equal to 0.46 and 0.508 , which leads to an average value equal to $0.48 \pm 0.025$.

\subsection{Model Description}

The bolted component is simulated using the finite element software Abaqus (Ref 63), in two steps. In the first step, the bolt is tightened, with a resulting force of $17 \mathrm{kN}$, taking advantage of the "bolt load" method of Abaqus standard. In the second step, the tightening is preserved and a displacement is imposed at the external upstream stator surface while the external downstream

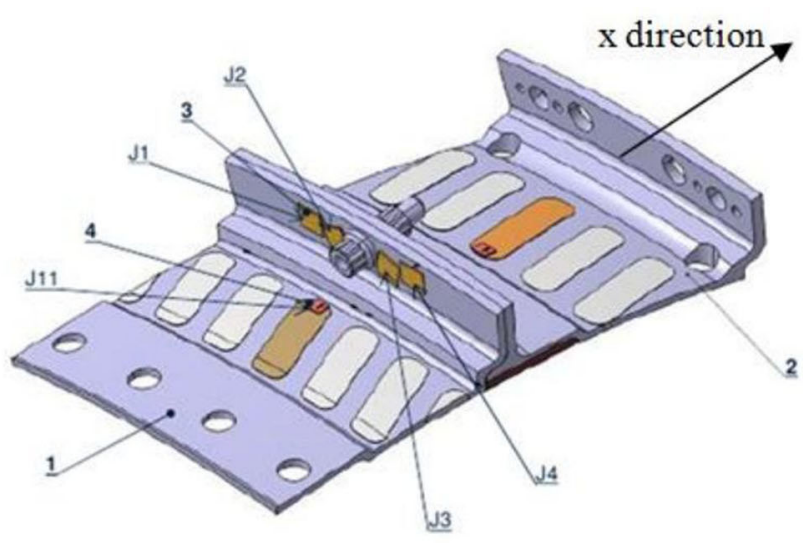

(a)

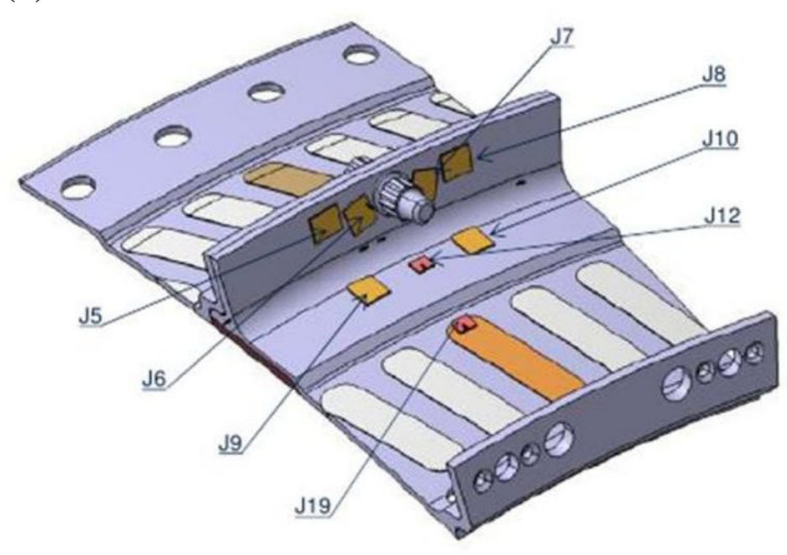

(b)

Fig. 12 Position of the different strain gages $(\mathrm{J} 1 \rightarrow \mathrm{J} 19)$

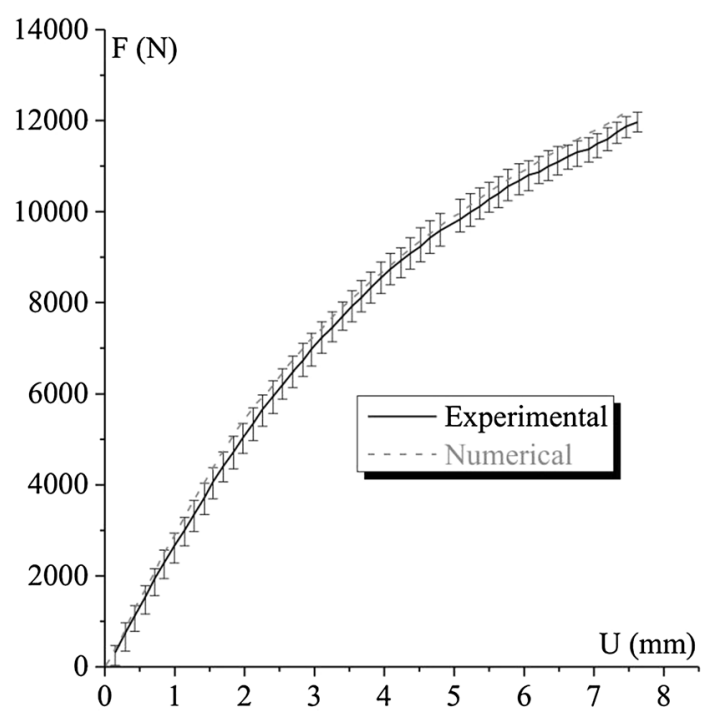

Fig. 13 Comparison between experimental and numerical results: average global tensile force $F$-displacement curve on the bolted sector $U$ 


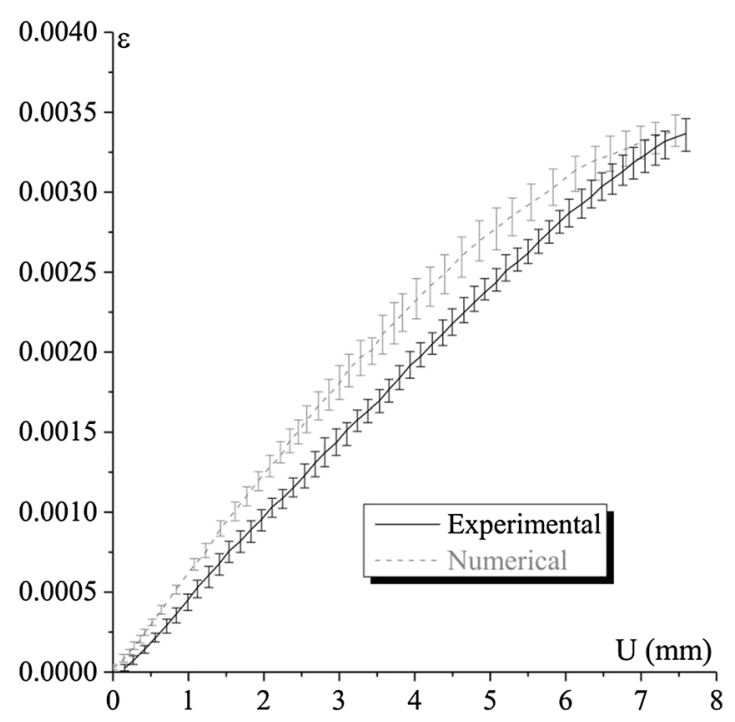

(a)

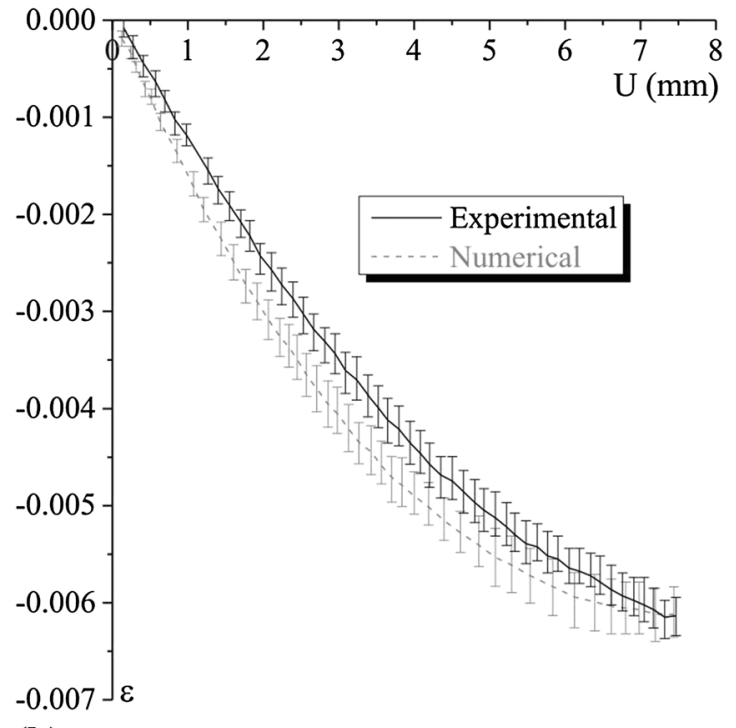

(b)

Fig. 14 Comparison between experimental and numerical results from gage number 1: (a) evolution of the maximum strain $\varepsilon$ as a function of displacement and (b) evolution of the minimum strain $\varepsilon$ as a function of displacement

stator surface is clamped as depicted in Fig. 9(b). The displacement is imposed at a constant velocity of $4.5 \times 10^{-3} \mathrm{~mm} / \mathrm{s}$ which corresponds to the velocity imposed in the experiments performed on identical Ti-6Al-4V components.

The Norton-Hoff material law is used with Abaqus through a UHARD interface in order to model the flanges. Note that with the Norton-Hoff law, the yield stress value tends toward zero when the strain rate tends to zero. In order to avoid immediate onset of plasticity at the beginning of the simulation, the minimum allowed strain rate for the yield stress evaluation is imposed to be $10^{-5} \mathrm{~s}^{-1}$ which corresponds to the lowest velocity used in the material tests. The evaluation of the fracture criterion is carried out by postprocessing the results at the end of each time increment using a Python script. Post-processing consists in evaluating the components of the Thomason criterion of Eq 15 on the basis of the strain and stress values and of the parameters of the damage model calibrated in section 4.4. In order to assess the risk of failure, a new state variable is introduced. This "damage indicator" is computed at each integration point and at the end of each time increment. It is defined based on the comparison of the left and right members of Eq 15:

damage indicator

$$
=\left\{\begin{array}{l}
0 \text { if } \frac{(2 / 3) T+1}{1-\chi^{2}}<\alpha\left(\frac{1-\chi}{\chi W}\right)^{2}+1.24 \frac{1}{\sqrt{\chi}} \\
\frac{(2 / 3) T+1}{1-\chi^{2}}-\alpha\left(\frac{1-\chi}{\chi W}\right)^{2}-1.24 \frac{1}{\sqrt{\chi}} \quad \text { otherwise }
\end{array} .\right.
$$

The damage indicator is equal to zero as long as coalescence is not reached and equal to the difference between the left and the right hand sides of Eq 15 after coalescence.

The mesh contains $\sim 120 \times 10^{3}$ s order tetrahedral elements with a typical size of $\sim 0.75 \mathrm{~mm}$ locally around the bolt. This
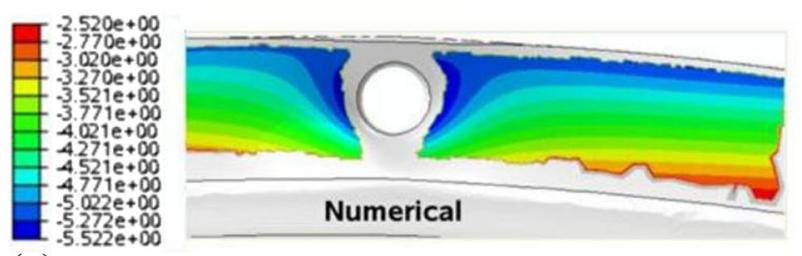

(a)

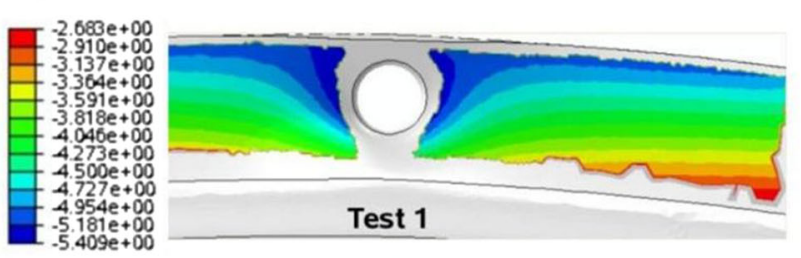

(b)

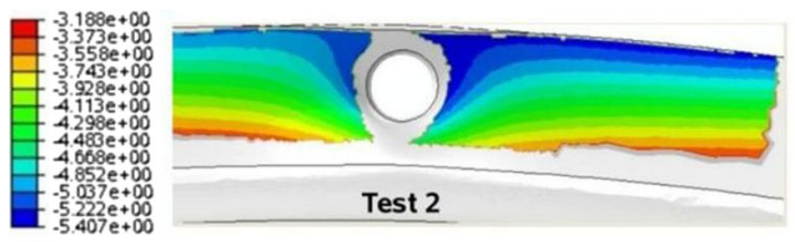

(c)

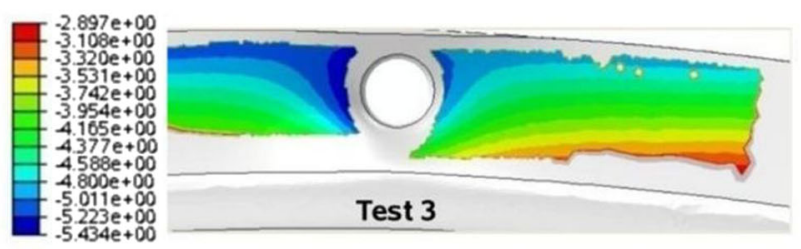

(d)

Fig. 15 Displacement fields in the direction $\times$ at a force level equal to $10,437 \mathrm{~N}$, correlation between numerical prediction and experimental tests: (a) numerical prediction, (b) experimental test number 1, (c) experimental test number 2 , and (d) experimental test number 3 
mesh was shown to provide converged results while maintaining a reasonable CPU time. Three finite elements are used through the thickness to capture the bending behavior. Contact between the two flanges and between the flanges and the bolt is taken into account using Coulomb static friction. The friction coefficient is equal to 0.4 for all contacts which avoids relative sliding of the different bodies during the simulation.

\subsection{Validation of the Norton-Hoff Model on the Industrial Application: Comparison Between the Experimental Results and the Numerical Predictions}

Several experimental tests have been performed on bolted sectors of a stator component (see Fig. 12) at the University of Liège. To gather as many data as possible in order to compare numerical predictions and experiments, both digital image correlation and strain gages were used to estimate the deformation fields. A stereoscopic technique has been used to measure the displacement (Vic3D). Reaction forces were recorded by load cells. The mean values and standard deviation have been extracted when analyzing the data and representative field histories. The results are given in the following form:

- force/displacement response

- maximum/minimum principal strain in the area of the different strain gages

- mean displacements in each direction
- images of the displacement in the x-direction at two levels of deformation when possible.

5.3.1 Global Validation. Figure 13 compares the experimental versus predicted overall force/displacement responses. The experimental result is a mean curve extracted from three different tests. Maximum and minimum values are indicated by error bars. A very good agreement between experimental measurements and numerical predictions is observed at this global level.

5.3.2 Local Validation. The focus is first on the minimum and maximum strain levels measured by gage 1 and on the comparison with the numerical predictions (see Fig. 12 for the identification of the position of gage 1). The experimental curve of Fig. 14 is constructed in the same way as the curve of Fig. 13 while the numerical curve is determined as the average of the different curves over the different integration points of the zone corresponding to the gage position. Figure 14 shows the evolution of(a) the maximum and (b) minimum values (involving error bars) as function of the displacement, with a relatively good agreement between the predictions and experimental data. A similar agreement between experiments and predictions is obtained with the other gages. Figure 15 compares the numerically predicted displacement field at a given force level compared to the experimental displacement field determined by stereoscopy at the same force level, showing again a good match. The numerical force level is chosen equal to $10,437 \mathrm{~N}$ in order to conform to the experimental force.

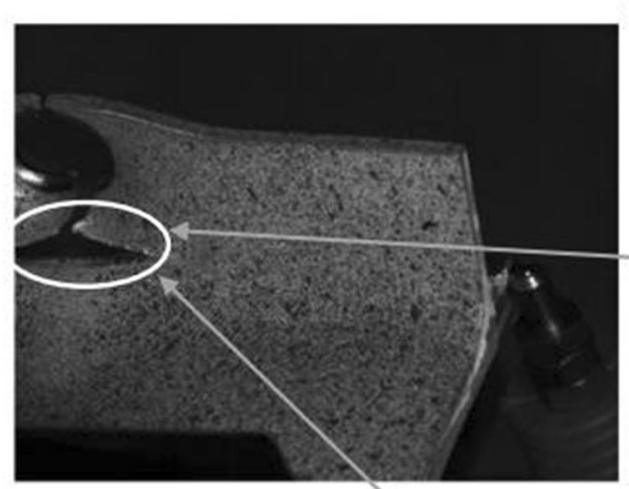

(a)

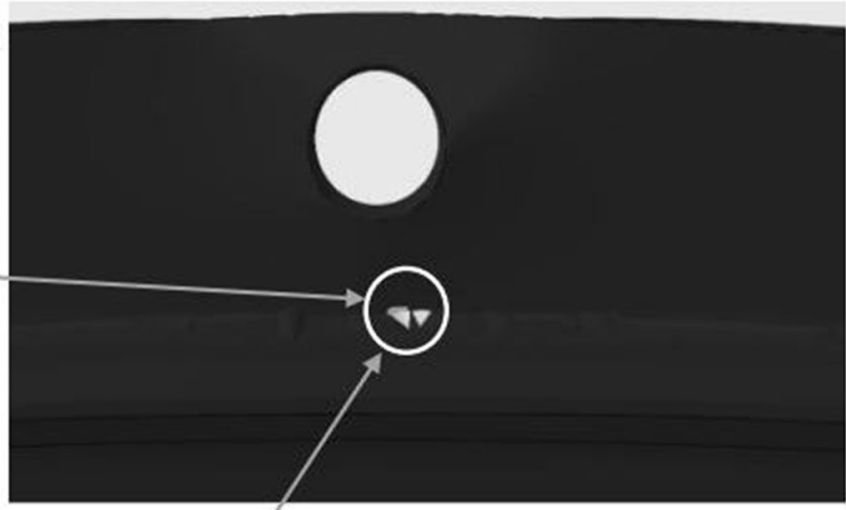

(b)

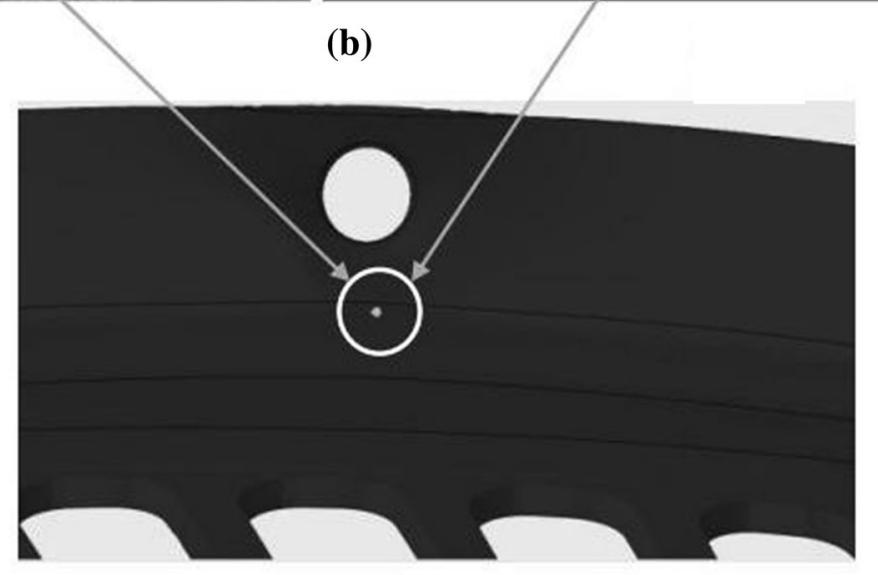

(c)

Fig. 16 Fracture of the aircraft engine stators: comparison between the experimental results and the numerical predictions for the force level when experimental rupture occurred (Ti-6Al-4V): (a) experimental result, (b) the numerical damage indicator (back view), and (c) the numerical damage indicator (front view) 


\subsection{Prediction of the Mechanical Response of an Aircraft Engine Stator}

In order to predict the mechanical response of an aircraft engine stator, the micromechanical damage model proposed and calibrated in section 2 is used to compare both Ti-6Al-4V and Ti5553 materials. The damage is attained when the coalescence condition of $\mathrm{Eq} 15$ is fulfilled. The possible fracture of the Inconel 718 bolt is ignored here (i.e., this alloy is assumed to have an elastoviscoplastic behavior without damage). The fracture of Inconel 718 is not an issue as the design used in the testing configuration was such it would not induce cracking in the bolts.

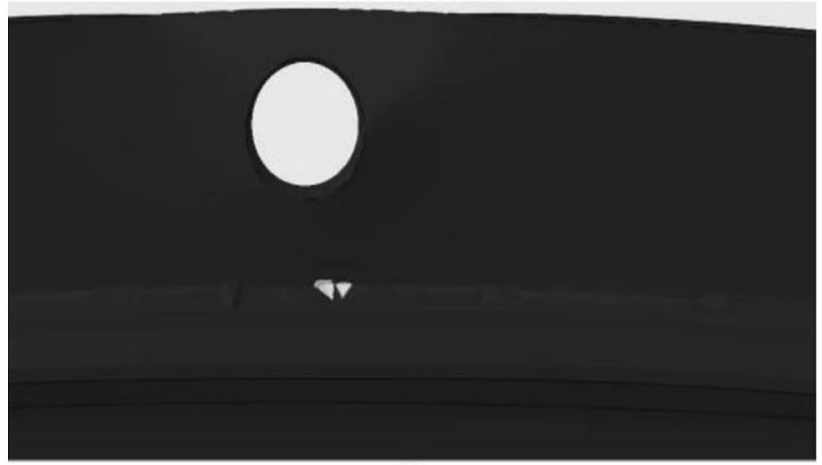

(a)

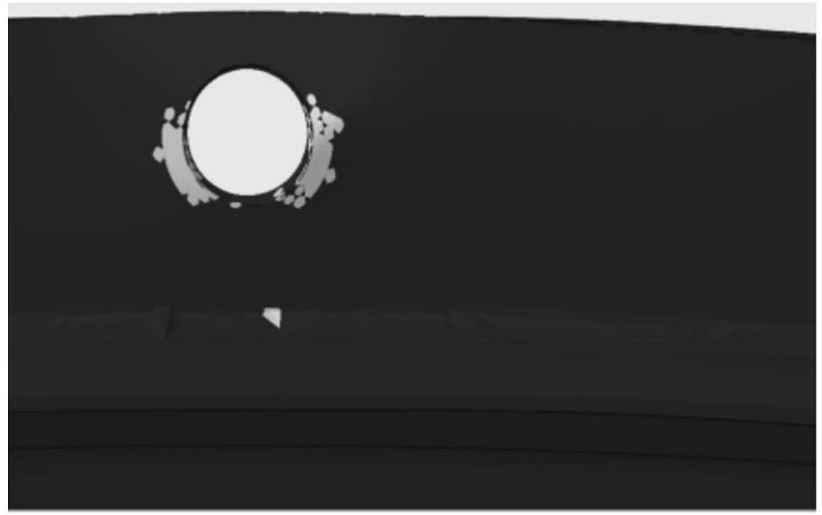

(b)

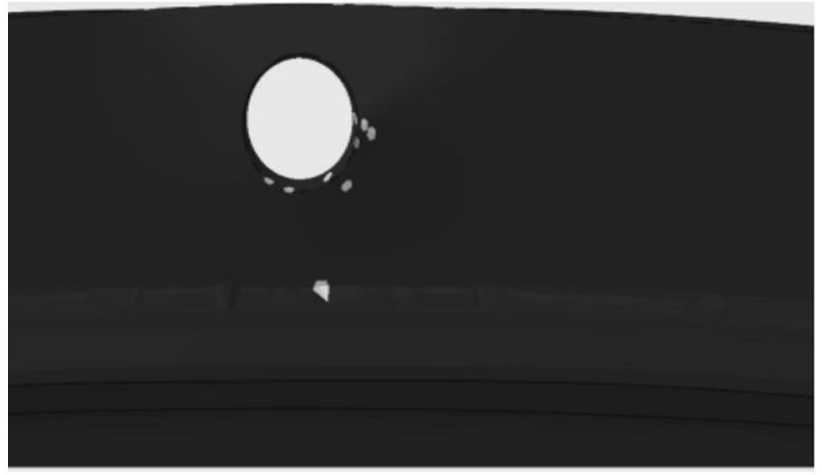

(c)

Fig. 17 Comparison between the different titanium alloys: numerical prediction of the damage indicator at an external force of 12,066 N: (a) Ti-6Al-4V (back view), (b) Ti5553-1 (back view), and (c) Ti5553-3 (back view)
Most of the high stress values are supported by the flanges in the vicinity of the bolt. The maximum strain level measured in the upstream flange is a factor 2 larger than the maximum strain level measured in the downstream flange. For these reasons, attention is focused on the upstream flange in the following analysis.

Figure 16(a) shows an experimental image of the component after fracture while Fig. 16(b) and (c) correspond to contour plot of the damage indicator at the instant when the force (in the computation) reaches the value of the force at failure (in the experiment). In these figures, the black color refer to elements in which the damage criterion is not verified (damage indicator $=0$ ). However, the other colors (different from black color) refer to elements where damage is accumulating. Figure 16(b) and (c) shows that failure is attained in a small zone at this force level. Furthermore, comparison between tests and simulations indicates that the failure scenario of the components is relatively well respected with failure occurring in the same region.

In order to compare the performances of Ti-6Al-4V with Ti5553 and to evaluate the potential for replacing the first by one of the latter, several simulations have been performed at RT. The results are presented in Fig. 17. The damage indicator is represented at an external force of $12,066 \mathrm{~N}$ (which corresponds to the experimental force of failure of the alloy Ti-6Al-4V) for the different alloys. From this figure, it is not obvious to find a trend about which material would be more prone to fail, proving that there are no negative signs for considering the alloy Ti5553 in this application. Moreover, the

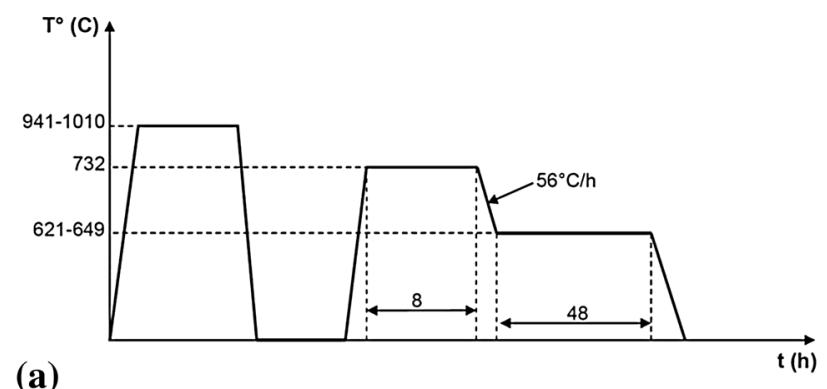

(a)

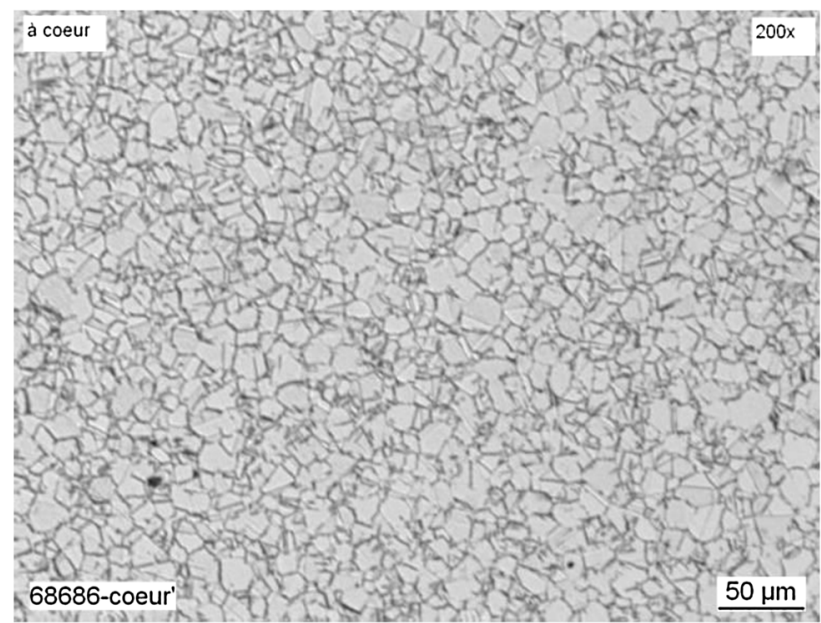

(b)

Fig. 18 Presentation of the Inconel 718 alloy: (a) final heat treatment cycle and (b) typical microstructure 
Table 11 Chemical composition of Inconel 718 alloy (values are in wt.\%)

\begin{tabular}{|c|c|c|c|c|c|c|c|c|c|c|}
\hline & $\mathrm{C}$ & & Mn & $\mathbf{S i}$ & $\mathbf{P}$ & $\mathbf{S}$ & $\mathrm{Cr}$ & $\mathbf{N i}$ & Mo & $\mathrm{Cu}$ \\
\hline Bottom & 0.028 & & 0.07 & 0.08 & 0.007 & $>0.001$ & 18.4 & 52.57 & 2.9 & 0.04 \\
\hline \multirow[t]{2}{*}{ Top } & 0.025 & & 0.07 & 0.08 & 0.007 & 0.001 & 18.5 & 52.4 & 2.9 & 0.04 \\
\hline & Co & Al & $\mathbf{T i}$ & B & $\mathbf{C b}+\mathbf{T a}$ & Ag & $\mathbf{F e}$ & $\mathbf{B i}$ & & $\mathbf{P b}$ \\
\hline Bottom & 0.2 & 0.57 & 1 & 0.0039 & 5.4 & $>2 \times 10^{-4}$ & 18.57 & $>3 \times 10^{-5}$ & & $>3 \times 10^{-4}$ \\
\hline Top & 0.2 & 0.56 & 1 & 0.0039 & 5.3 & $>2 \times 10^{-4}$ & 18.57 & $>3 \times 10^{-5}$ & & $>3 \times 10^{-4}$ \\
\hline
\end{tabular}

experimental data on Ti-6Al-4V components are quite dispersed and averaged values had to be taken.

\section{Conclusions}

Several experimental tests have been carried out in order to study and to analyze fracture by nucleation, growth, and coalescence of voids in three different titanium alloys. The experiments show that the ductility of Ti-6Al-4V is higher than the ductility of two different Ti-5553 microstructures. The experimental fracture strain exhibits large dispersions. This dispersion is probably induced by uncontrolled local heterogeneities in grain size, texture, or $\alpha$ macrozones. A damage model has been developed and the corresponding material parameters have been calibrated. This model describes the three main damage phases: void nucleation (Beremin model), void growth (Rice and Tracey model), and void coalescence (Thomason model). The model indicates that the significantly larger fracture strain in the Ti5553-3 microstructure compared to the Ti5553-1 microstructure is the result of a better resistance to void nucleation. The calibrated elastoviscoplastic parameters are used in complex simulations of a bolted sector of an aircraft engine stator in order to compare the numerical force predictions with experimental results. These comparisons are satisfactory. They validate the model for further applications and prove the potential for using the Ti5553 alloy in similar components.

\section{Acknowledgments}

The authors thank the Walloon Region (Titaero Project), the Belgian Scientific Research Fund FNRS which finances A.M. Habraken and the Interuniversity Attraction Poles Program, Belgian Science Policy P7/21, for financial support.

\section{Appendix 1: Additional Data on Inconel 718 Alloy}

\section{General Description}

Inconel 718 alloy is a high-strength, corrosion-resistant nickel chromium material. This alloy is used for jet engine and high-speed airframe parts such as wheels, buckets, spacers, and high temperature bolts and fasteners.

\section{As-Received Material}

The material used for the current study is an Inconel 718 alloy received from Techspace Aero in the form of round bar with a diameter equal to $40 \mathrm{~mm}$ and a length equal to $150 \mathrm{~mm}$.

\section{Heat Treatment}

The heat treatment used to generate Inconel 718 alloy is defined by the heat cycles of Fig. 18(a).

A detailed description of the heat treatment cycle is given in the following points:

- heat from room temperature up to a temperature between 941 and $1010^{\circ} \mathrm{C}$.

- hold at the latter temperature during a sufficient time dependent on the thickness of the received material.

- air cooling.

- aging at $732^{\circ} \mathrm{C}$ during $8 \mathrm{~h}$.

- cooling with a constant temperature rate equal to $56^{\circ} \mathrm{C} / \mathrm{h}$ up to a temperature between 621 and $649{ }^{\circ} \mathrm{C}$.

- aging at the last temperature during $48 \mathrm{~h}$.

- air cooling.

\section{Chemical Composition}

The chemistry of Inconel 718 alloy used in this study is reported in Table 11 .

\section{Microstructure of Inconel 718 Alloy}

The typical microstructure of Inconel 718 alloy is given in Fig. 18(b).

\section{References}

1. R.R. Boyer and R.D. Briggs, The Use of $\beta$ Titanium Alloys in the Aerospace Industry, J. Mater. Eng. Perform., 2005, 14, p 681-685

2. P.-J. Arrazola, A. Garay, L.-M. Iriarte, M. Armendia, S. Marya, and F. Le Maitre, Machinability of Titanium Alloys (Ti-6Al-4V and Ti555.3), J. Mater. Process. Technol., 2009, 209, p 2223-2230

3. J. Lemaitre, A Continuous Damage Mechanics Model for Ductile Fracture, J. Eng. Mater. Technol., 1985, 107, p 83-89

4. J. Lemaître and J.L. Chaboche, Mécanique des Matériaux Solides, Dunod, Paris, 1985 [in French]

5. A.L. Gurson, Continuum Theory of Ductile Rupture by Void Nucleation and Growth. Part I: Yield Criteria and Flow Rules for Porous Ductile Media, J. Eng. Mater. Technol. Trans. ASME, 1977, 99, p $2-15$

6. V. Tvergaard and A. Needleman, Analysis of the Cup-Cone Fracture in a Round Tensile Bar, Acta Metall., 1984, 32, p 157-169

7. A.A. Benzerga, J. Besson, and A. Pineau, Anisotropic Ductile Fracture: Part II: Theory, Acta Mater., 2004, 52, p 4639-4650

8. F. Scheyvaerts, P.R. Onck, C. Tekoglu, and T. Pardoen, The Growth and Coalescence of Ellipsoidal Voids in Plane Strain Under Combined Shear and Tension, J. Mech. Phys. Solids, 2011, 59, p 373-397

9. T. Pardoen, F. Scheyvaerts, A. Simar, C. Tekoğlu, and P.R. Onck, Multiscale Modeling of Ductile Failure in Metallic Alloys, C.R. Phys., 2010, 11, p 326-345 
10. G. Le Roy, J.D. Embury, G. Edward, and M.F. Ashby, A Model of Ductile Fracture Based on the Nucleation and Growth of Voids, Acta Metall., 1981, 29, p 1509-1522

11. G.R. Johnson and W.H. Cook, Fracture Characteristics of Three Metals Subjected to Various Strains, Strain Rates, Temperatures and Pressures, Eng. Fract. Mech., 1985, 21, p 31-48

12. F.A. McClintock, S.M. Kaplan, and C.A. Berg, Ductile Fracture by Hole Growth in Shear Bands, Int. J. Fract. Mech., 1966, 2, p 614-627

13. J.R. Rice and D.M. Tracey, On the Ductile Enlargement of Voids in Triaxial Stress Fields, J. Mech. Phys. Solids, 1969, 17, p 201-217

14. T. Pardoen, I. Doghri, and F. Delannay, Experimental and Numerical Comparison of Void Growth Models and Void Coalescence Criteria for the Prediction of Ductile Fracture in Copper Bars, Acta Mater, 1998, 46(2), p 541-552

15. T. Pardoen and F. Delannay, Assessment of Void Growth Models from Porosity Measurements in Cold Drawn Copper Bars, Metall. Mater. Trans. A, 1998, 29(A), p 1895-1909

16. B. Marini, F. Mudry, and A. Pineau, Experimental study of cavity growth in ductile rupture, Eng. Fract. Mech., 1985, 22, p 989-996

17. R. Becker, A. Needleman, O. Richmond, and V. Tvergaard, Void Growth and Failure in Notched Bars, J. Mech. Phys. Solids, 1988, 36(3), p 317-351

18. G. Huber, Y. Brechet, and T. Pardoen, Predictive Model for Void Nucleation and Void Growth Controlled Ductility in Quasi-eutectic Cast Aluminium Alloys, Acta Mater., 2005, 53, p 2739-2749

19. D. Lassance, D. Fabregue, F. Delannay, and T. Pardoen, Micromechanics of Room and High Temperature Fracture in 6xxx Al Alloys, Prog. Mater. Sci., 2007, 52, p 62-129

20. M. Ben Bettaieb, Th. Van Hoof, Th. Pardoen, Ph. Dufour, A. Lenain, P.J. Jacques, A.M. Habraken, On the Mechanical Behavior of Ti5553 Alloy: Elasticity and Viscoplasticity, Mater. Sci. Eng. A (accepted)

21. R. Boyer, G. Welsch, and E.W. Collings, Materials Properties Handbook, Titanium Alloys, ASM International, Materials Park, 1994, p 483

22. G. Lutjering and J.C. Williams, Titanium, Springer, Berlin, 2003

23. S.L. Semiatin, V. Seetharaman, and I. Weiss, Hot Workability of Titanium and Titanium Aluminide Alloys-An Overview, Mater. Sci. Eng., 1998, 243(A), p 1-24

24. R. Ding, Z.X. Guo, and A. Wilson, Microstructural evolution of a Ti6Al-4V alloy during thermomechanical processing, Mater. Sci. Eng. A, 2002, 327, p 233-245

25. Y. Millet, Journées Technologiques titane, The French Titanium Association, Nantes, 2007 [in French]

26. F.H. Norton, Creep of Steel at High Temperatures, Mc Grow-Hill, New-York, 1929, p 219

27. N.J. Hoff, Approximate Analysis of Structures in the Presence of Moderately Large Creep Deformations, Q. Appl. Mech., 1954, 12, p 49-55

28. J.J. Brioist, Un modèle thermomécanique du refroidissement des pièces de fonderie, PhD Thesis, Ecole Nat. Sup. des Mines de Paris, 1995 [in French]

29. M. Vanderhasten, L. Rabet, and B. Verlinden, Ti-6Al-4V: Deformation Map and Modelisation of Tensile Behaviour, Mater. Des., 2008, 29, p 1090-1098

30. A. Simar, K.L. Nielsen, B. de Meester, V. Tvergaard, and T. Pardoen, Micro-mechanical Modelling of Ductile Failure in 6005A Aluminium Using a Physics Based Strain Hardening Law Including Stage IV, Eng. Fract. Mech., 2010, 77, p 2491-2503

31. N.N. Popov, A.G. Ivanov, and S.A. Morozov, Effect of Strain Rate on the Resistance of Titanium Alloy VT16 to Plastic Deformation, Probl. Prochnosti., 1986, 8, p 1045-1048

32. G.V. Stepanov and B.A. Kovalev, Effect of Strain Rate on Strength and Ductility of Titanium Alloys, Probl. Prochnosti., 1980, 5, p 47-49

33. W.S. Lee, T.H. Chen, C.F. Lin, and N.W. Lee, High Strain Rate Shear Deformation and Fracture Behaviour of Biomedical Titanium Alloy, Mater. Sci. Technol., 2010, 26, p 1079-1087

34. W.S. Lee, C.F. Lin, T.H. Chen, and H.H. Hwang, Effects of Strain Rate and Temperature on Mechanical Behaviour of Ti-15Mo-5Zr-3Al Alloy, J. Mech. Behav. Biomed. Mater, 2008, 1, p 336-344

35. J.D. Bryant, D.D. Makel, and H.G.F. Wilsdorf, Observations on the Effect of Temperature Rise at Fracture in Two Titanium Alloys, Mater. Sci. Eng., 1986, 77, p 85-93

36. N. Singh and V. Singh, Observations on the Effect of Temperature Rise at Fracture in Two Titanium Alloys, Mater. Sci. Eng. A, 2008, 485, p $130-139$
37. J.W. Hancock and A.C. Mackenzie, On the Mechanisms of Ductile Failure in High-Strength Steels Subjected to Multi-axial Stress-States, J. Mech. Phys. Solids, 1976, 24, p 147-169

38. A.C. Mackenzie, J.W. Hancock, and D.K. Brown, On the Influence of State of Stress on Ductile Failure Initiation in High-Strength Steels, Eng. Fract. Mech., 1977, 9, p 167-188

39. J.W. Hancock and D.K. Brown, On the Mechanisms of Ductile Failure in High-Strength Steels Subjected to Multi-axial Stress-States, J. Mech. Phys. Solids, 1983, 31, p 1-24

40. D. Holland, A. Halim, and W. Dahl, Influence of Stress Triaxiality Upon Ductile Crack Propagation, Steel Res., 1990, 61, p 504-506

41. M.S. Mirza, D.C. Barton, and P. Church, The Effect of Stress Triaxiality and Strain-Rate on the Fracture Characteristics of Ductile Metals, J. Mater. Sci., 1996, 31, p 453-461

42. P.W. Bridgman, The Stress Distribution at the Neck of a Tension Specimen, Trans. ASME, 1944, 32, p 553-574

43. Y.Y. Zhu, S. Cescotto, and A.M. Habraken, A Fully Coupled Elastoplastic Damage Modelling and Fracture Criteria in Metalforming Processes, J. Mater. Process. Technol., 1992, 32, p 197-204

44. Y. Yulan, W. Weiqi, L. Fengli, L. Weiqing, and Z. Yongqiang, The Effect of Aluminum Equivalent and Molybdenum Equivalent on the Mechanical Properties of High Strength and High Toughness Titanium Alloys, Mater. Sci. Forum, 2009, 618-619, p 169-172

45. H.J. Niu and I.T.H. Chang, Modeling the Effect of Porosity on Ductile Fracture of Powder Processed Titanium Alloy, Scripta Mater., 1999, 41, p 481-486

46. T.S. Srivatsan, M. Al-Hajri, M. Petraroli, B. Derreberry, and P.C. Lam, The Fracture Behavior of a Ti-6242 Alloy Deformed in Bending Fatigue, Mater. Sci. Eng. A, 2002, 334, p 327-333

47. R. Mythili, S. Saroja, and M. Vijayalakshmi, Study of Mechanical Behavior and Deformation Mechanism in an $\alpha-\beta$ Ti-4.4Ta-1.9Nb Alloy, Mater. Sci. Eng. A, 2007, 454-455, p 43-51

48. T. Pardoen and A. Pineau, In Comprehensive Structural Integrity Encyclopedia, Chap. 2, Vol 2, Elsevier, Amsterdam, 2007

49. F. Beremin, Cavity Formation from Inclusions in Ductile Fracture of A508 Steel, Met. Trans., 1981, 12(A), p 723-731

50. P.F. Thomason, Ductile Fracture of Metals, Pergamon Press, Oxford, 1990

51. D. Lassance, F. Scheyvaerts, and T. Pardoen, Growth and Coalescence of Penny-Shaped Voids in Metallic Alloys, Eng. Fract. Mech., 2006, 73, p 1009-1034

52. M.J. Worswick and R.J. Pick, Void Growth and Constitutive Softening in a Periodically Voided Solid, J. Mech. Phys. Solids, 1990, 38, p 601-625

53. Y. Huang, Accurate Dilatation Rates for Spherical Voids in Triaxial Stress Fields, J. Appl. Mech., 1991, 58, p 1084-1085

54. L. Lecarme, E. Maire, A. Kumar, C. De Vleeschouwer, L. Jacques, A. Simar, and T. Pardoen, Heterogenous Void Growth Revealed by In Situ 3-D X-ray Microtomography Using Automatic Cavity Tracking, Acta Mater, 2014, 63, p 130-139

55. T. Pardoen and J.W. Hutchinson, An Extended Model for Void Growth and Coalescence, J. Mech. Phys. Solids, 2000, 48, p 2467-2512

56. L. Lecarme, C. Tekoglu, and T. Pardoen, Void Growth and Coalescence in Ductile Solids with Stage III, and Stage IV Strain Hardening, Int. J. Plast., 2011, 27, p 1203-1223

57. K.L. Nielsen and V. Tvergaard, Ductile Shear Failure or Plug Failure of Spot Welds Modeled by Modified Gurson Model, Eng. Fract. Mech., 2010, 77, p 1031-1047

58. G. Yuan and X. Lu, An Active Set Limited Memory BFGS Algorithm for Bound Constrained Optimization, Appl. Math. Model., 2011, 35, p 3561-3573

59. Y. Xiao and H. Zhang, Modified Subspace Limited Memory BFGS Algorithm for Large-Scale Bound Constrained Optimization, $J$. Comput. Appl. Math., 2008, 222, p 429-439

60. N. Andrei, A Scaled BFGS Preconditioned Conjugate Gradient Algorithm for Unconstrained Optimization, Appl. Math. Lett., 2007, 20, p 645-650

61. J.L. Morales, A Numerical Study of Limited Memory BFGS Methods, Appl. Math. Lett., 2002, 15, p 481-487

62. L. Lecarme, Viscoplastic Effects on Damage and Fracture of Titanium Alloy Ti-6A1-4V, PhD Thesis, UCL 2013, Belgium

63. ABAQUS 6.9, Simulia, Inc., Providence, RI, USA, 2009 